\title{
Complete and Selective Cholinergic Denervation of Rat Neocortex and Hippocampus but Not Amygdala by an Immunotoxin against the p75 NGF Receptor
}

\author{
Stephan Heckers, ${ }^{1}$ Toshiyuki Ohtake, ${ }^{1}$ Ronald G. Wiley, ${ }^{2}$ Douglas A. Lappi, ${ }^{3}$ Changiz Geula, ${ }^{1}$ and Marek- \\ Marsel Mesulam ${ }^{1}$ \\ 'Bullard and Denny-Brown Laboratories, Department of Neurology, Beth Israel Hospital and Harvard Medical School, \\ Boston, Massachusetts 02215, ${ }^{2}$ Neurology Service (127), DVAMC, Nashville, Tennessee 37212-2637, and ${ }^{3}$ The Whittier \\ Institute, La Jolla, California 92037
}

The immunotoxin 192 lgG-saporin, produced by coupling the ribosome-inactivating protein saporin to the monoclonal 192 IgG antibody against the low-affinity p75 NGF receptor (NGFr), was injected into the cerebral ventricle, septal area, and substantia innominata of adult rats.

Injections into the cerebral ventricle induced a complete loss of NGFr-positive basal forebrain neurons and their axons. Extensive loss of cholinergic neurons was found in the septum, diagonal band, and magnocellular preoptic nucleus but not in the nucleus basalis-substantia innominata complex, where many cholinergic, presumably NGFr-negative, neurons remained intact. Cholinergic fibers were completely lost in the neocortex and hippocampus, showed some preservation in allocortical areas, and showed only minor loss in the amygdala. The NGFr-positive cholinergic basal forebrain neurons progressively degenerated during the first $5 \mathrm{~d}$ and did not recover after $180 \mathrm{~d}$. The effect of intraventricular 192 IgG-saporin injections on NGFr-positive basal forebrain neurons could be blocked by simultaneous intraventricular injection of colchicine.

Intraparenchymal injections into the septal area or substantia innominata damaged cholinergic neurons mainly around the injection sites and reduced their respective cortical and hippocampal projections.

Noncholinergic septal neurons containing parvalbumin and noncholinergic neurons containing calbindin- $D_{28 \mathrm{~K}}$ or NADPHd, which were adjacent to cholinergic nucleus basalis-substantia innominata neurons, were not affected by 192 IgGsaporin. The ChAT immunoreactivity in cortical interneurons, habenula, and brainstem was unchanged. Dopaminergic and noradrenergic cortical afferents remained intact.

\footnotetext{
Received May 18, 1993; revised Aug. 6, 1993; accepted Aug. 13, 1993.

S.H. thanks Dr. Christine Konradi for continuous support during the study. We express our gratitude for the generous supply of antibodies to Drs. Mark Bothwell, University of Washington, Seattle (p75 NGFr); Marco Celio, University of Fribourg, Switzerland (calbindin-D , ); Louis B. Hersh, University of Kentucky, Lexington (ChAT); and Bruce H. Wainer, University of Chicago, Chicago (Ab8). This work was supported in part by NIA Grant AG 10282, Javits Neuroscience Investigator Award (NS 20285), the Department of Veterans Affairs Medical Research Service, the NIH (DK-18811), and the Whittier Angiogenesis Research Program. S.H. was supported by the Deutsche Forschungsgemeinschaft and the Marcia Simon Investigator Award of the National Alliance for Research on Schizophrenia and Depression.

Correspondence should be addressed to Dr. Stephen Heckers, Department of Neurology, Beth Israel Hospital, 330 Brookline Avenue, Boston, MA 02215.

Copyright $@ 1994$ Society for Neuroscience $0270-6474 / 94 / 141271-19 \$ 05.00 / 0$
}

192 IgG-saporin damaged two neuronal groups outside the basal forebrain that express the p75 NGF receptor: NGFrpositive cerebellar Purkinje cells after intraventricular injection and cholinergic striatal interneurons after injections into the substantia innominata.

These results indicate that the immunotoxin 192 lgG-saporin induces a complete and selective lesion of NGFr-positive cholinergic basal forebrain neurons projecting to hippocampus and neocortex.

[Key words: ChAT, NGF receptor, immunohistochemistry, AChE histochemistryl

The cholinergic neurons in the basal forebrain give rise to a dense network of cholinergic fibers innervating the entire cortical mantle, the hippocampus, the amygdala, and some thalamic nuclei (for review, see Mesulam, 1988; Wainer and Mesulam, 1990). Inhibiting the modulatory effect of cholinergic neurons on their target neurons has been shown to affect several behavioral domains, especially learning and memory (Olton and Wenk, 1987; Dekker et al., 1991; Dunnett et al., 1991; Fibiger, 1991).

One widely used method to study the role of cholinergic neurotransmission in learning and memory has been to lesion the cholinergic basal forebrain neurons. Lesions have been produced either by physical means (radiofrequency lesion, electrolytic lesion) or by the injection of relatively more specific neurotoxic substances that damage neurons but not passing fibers (for review, see Olton and Wenk, 1987; Dekker et al., 1991).

Chemical lesion models of the cholinergic basal forebrain system have used four different strategies: (1) basal forebrain injections of excitatory amino acids (for review, see Dekker et al., 1991; Reine and Nieoullon, 1992), (2) injections of the aziridinium ion of ethylcholine mustard (AF64A) into the basal forebrain or target areas of cholinergic neurons (e.g., Fisher and Hanin, 1986; McGurk et al., 1987; Nakamura et al., 1992), (3) intracerebral or systemical injections of murine monoclonal antibodies against AChE (Bean et al., 1991; Rakonczay et al., 1993), and (4) intraventricular or intraparenchymal injections of a toxin (diphtheria toxin or the ribosome-inactivating protein saporin; Lappi et al., 1985) coupled to a monoclonal antibody directed against the p75 NGF receptor (NGFr) (Kudo et al., 1989; Imaizumi et al., 1991; Wiley et al., 1991; Book et al. 1992; Nilsson et al., 1992; Wiley, 1992).

The $\mathrm{p} 75 \mathrm{NGF}$ receptor is a $75 \mathrm{kDa}$ transmembrane protein without tyrosine kinase activity that binds all neurotrophins 


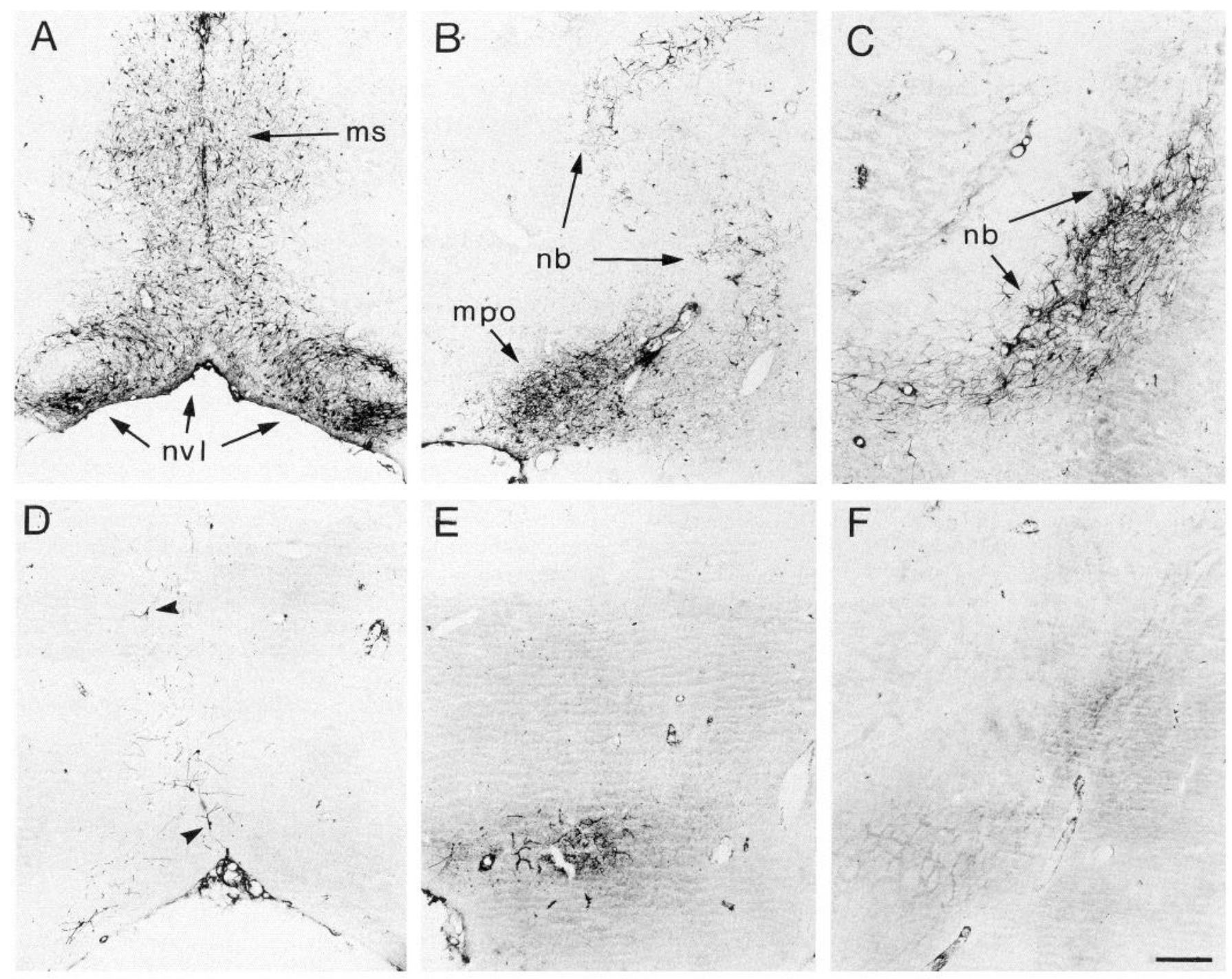

Figure 1. Extensive loss of NGFr-positive basal forebrain neurons after intraventricular $192 \mathrm{IgG}$-saporin injection. $A-C$, NGFr-positive neurons in the medial septum $(m s)$, nucleus of the vertical limb of the diagonal band $(n v l)$, medial preoptic nucleus $(m p o)$, and nucleus basalis $(n b) 22 \mathrm{~d}$ after intraventricular saline injection. $D-F$, Matching sections demonstrate an almost complete loss of NGFr-positive basal forebrain neurons 22 d after intraventricular $192 \mathrm{IgG}$-saporin injection. Occasionally, very few NGFr-positive neurons were found (arrowheads in D). Scale bar, $300 \mu \mathrm{m}$.

known to date; NGF, brain-derived neurotrophin factor, and neurotrophin-3, -4, and -5 (Bothwell, 1991a; Chao, 1992). Most importantly, for the present study, the cholinergic basal forebrain neurons have been shown to express by far the highest level of p75 NGFr immunoreactivity in the adult rat brain (Kiss et al., 1988; Koh et al., 1989; Woolf et al., 1989; Yan and Johnson, 1989; Pioro and Cuello, 1990a,b; Bothwell, 1991b). Furthermore, it was demonstrated that the p 75 NGF receptor mediates the retrograde transport of both neurotrophins and a monoclonal antibody against the $\mathrm{p} 75 \mathrm{NGF}$ receptor (Schweitzer, 1987; Altar and Bakhit, 1991; Ferguson et al., 1991). Therefore, injection of a toxin-coupled antibody targeting this epitope was regarded as a very promising lesion model of the cholinergic basal forebrain system (Wiley, 1992).

Here we report on the extent, time course, specificity, and mechanism of the cholinergic basal forebrain lesion induced by intraventricularly or intraparenchymally injected saporin, coupled to an antibody against the p75 NGF receptor (192 IgGsaporin), in the adult rat CNS.

\section{Materials and Methods}

\section{Animals and injections}

Eighty-one male albino Sprague-Dawley rats $(250-400 \mathrm{gm})$ were used for stereotaxically placed injections of a $0.42 \mathrm{mg} / \mathrm{ml}$ solution of 192 IgG-saporin, a solution of the monoclonal antibody $192 \mathrm{IgG}$, a $0.06 \mathrm{M}$ ibotenic acid solution, a $0.1 \mathrm{~m}$ quisqualic acid solution, or a $0.9 \%$ saline solution. The production of the $192 \mathrm{IgG}$-saporin solution is described elsewhere (Wiley et al., 1991; Wiley and Lappi, 1993).

Animals were anesthetized with $6.5 \mathrm{mg} / 100 \mathrm{mg}$ body weight sodium pentobarbital and placed in a stereotaxic apparatus. For each injection, a hole was drilled in the skull and a microliter syringe filled with toxin or saline solution was lowered at three different locations. Coordinates were taken from Paxinos and Watson (1986)

Intraventricular injections. $192 \mathrm{IgG}$-saporin solution $(4-10 \mu \mathrm{l})$ was injected at $\mathrm{AP}-1.0, \mathrm{ML}+1.5$, and $\mathrm{DV}-4.5$ relative to bregma $(n=$ 16). Control animals $(n=9)$ received equivalent amounts of saline.

Septal injections. $192 \mathrm{IgG}$-saporin solution $(0.3-0.5 \mu \mathrm{l})(n=9)$ or saline $(n=5)$ was injected into the septal nuclei at an angle of $15^{\circ}$ at $\mathrm{AP}+0.6, \mathrm{ML}-1.5$, and $\mathrm{DV}-6.7$ relative to bregma.

Substantia innominata injections. $192 \mathrm{IgG}$-saporin solution $(0.3-0.7$ $\mu \mathrm{l})(n=25), 1 \mu \mathrm{l}$ solution of the monoclonal antibody $192 \mathrm{IgG}$ against the p75 NGF receptor $(n=4), 1 \mu$ l ibotenic acid solution $(n=1), 1 \mu$ l 

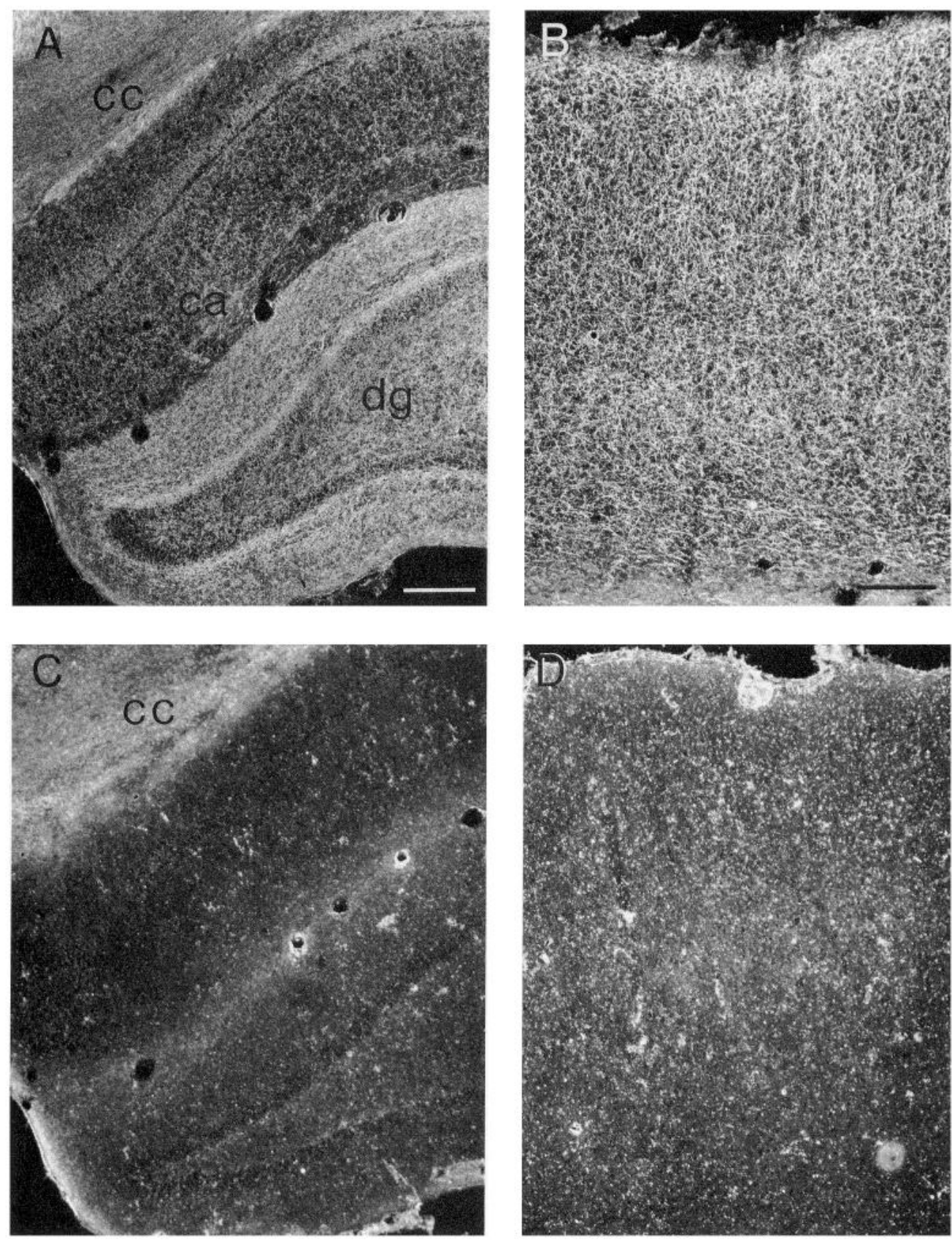

Figure 2. Complete loss of NGFrpositive hippocampal and cortical afferents after intraventricular 192 IgGsaporin injection (dark-field photomicrograph). $A$ and $B$, NGFr-positive fibers in the dentate gyrus $(d g)$ and cornu ammonis $(\mathrm{ca})(A)$ and occipital cortex (B) $22 \mathrm{~d}$ after intraventricular saline injection. $C$ and $D$, Matching sections show a complete loss of NGFr-positive afferents $22 \mathrm{~d}$ after intraventricular 192 IgG-saporin injection. Scale bars: $A, 200$ $\mu \mathrm{m}$ for $A$ and $C ; B, 150 \mu \mathrm{m}$ for $B$ and $D$. quisqualic acid solution $(n=9)$, or $0.3 \mu$ l saline solution $(n=3)$ was injected into the substantia innominata at $\mathrm{AP}-0.9, \mathrm{ML} \pm 2.8$, and $\mathrm{DV}$ -7.2 relative to bregma.

Intraventricular and septal injections were always single injections; substantia innominata injections were performed unilaterally as well as bilaterally. Animals were allowed to survive for $1,2,3,4$, or $5 \mathrm{~d}$ ( $n=$ 2 for each group), $7 \mathrm{~d}(n=13), 14 \mathrm{~d}(n=5), 22 \mathrm{~d}(n=37), 28 \mathrm{~d}(n=$ $7)$, or $180 \mathrm{~d}(n=9)$.

\section{Preparation of tissue sections}

Animals were anesthetized with an overdose of sodium pentobarbital (13 mg/100 mg body weight) and perfused transcardially with 50-100 $\mathrm{ml} 0.9 \%$ saline, followed by either $4 \%$ paraformaldehyde in $0.1 \mathrm{M}$ phosphate buffer ( $\mathrm{pH} 7.4)$, or $4 \%$ paraformaldehyde with $0.5 \%$ glutaraldehyde and $15 \%$ saturated picric acid solution in $0.1 \mathrm{~m}$ phosphate buffer (pH 7.4) for $20 \mathrm{~min}$, and finally with $100 \mathrm{ml}$ of a $10 \%$ sucrose solution.

Some brains were not perfused with the $10 \%$ sucrose solution but were postfixed in the $4 \%$ paraformaldehyde with $0.5 \%$ glutaraldehyde and $15 \%$ saturated picric acid solution in $0.1 \mathrm{M}$ phosphate buffer for 2 hr. All brains were immersed in a $30 \%$ sucrose solution overnight at $4^{\circ} \mathrm{C}$, cut on a freezing microtome into $40-\mu \mathrm{m}$-thick sections, and stored in a $0.1 \mathrm{M}$ phosphate buffer solution containing $0.02 \%$ sodium azide at $4^{\circ} \mathrm{C}$.

\section{Stains}

One series of sections per animal was mounted on chromalum-subbed slides, air dried, and Nissl stained in a $0.1 \%$ cresyl violet solution for $5 \mathrm{~min}$.

Enzyme histochemistry. One series of sections per animal was mounted on chromalum-subbed slides, air dried, and stained for acetylcholinesterase (AChE) using the Tago modification of the Karnovsky-Roots histochemical procedure (Tago et al., 1986; Mesulam and Moran, 1987). Briefly, sections were rinsed in $0.1 \mathrm{M}$ maleate buffer, $\mathrm{pH} 8.0$, and then incubated in a solution of $0.053 \mathrm{gm}$ of acetylthiocholine iodide, 0.147 $\mathrm{gm}$ of sodium citrate, $0.075 \mathrm{gm}$ of cupric sulfate, and $0.0164 \mathrm{gm}$ of potassium ferricyanide in 1 liter of the $0.1 \mathrm{~m}$ maleate buffer. To inhibit 

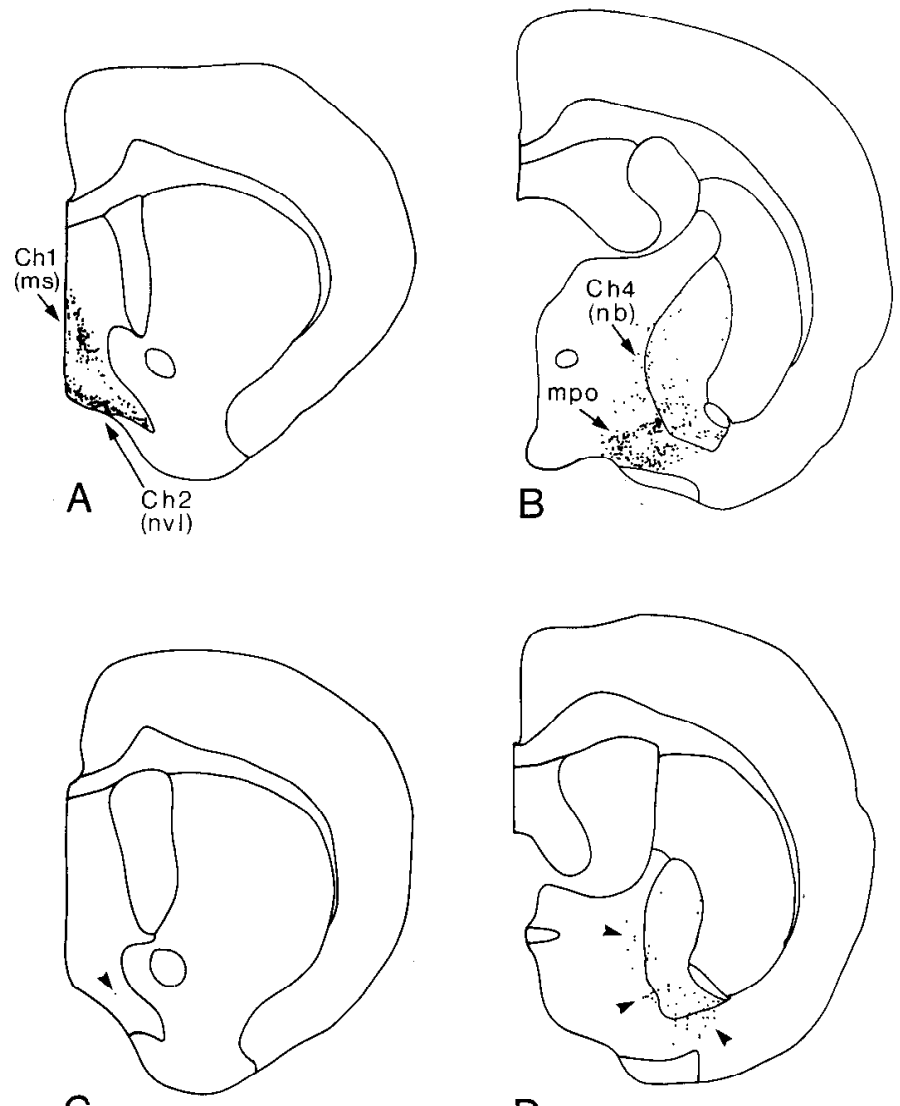

C

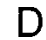

Figure 3. Distribution of ChAT-positive basal forebrain neurons in rats $22 \mathrm{~d}$ after intraventricular saline or $192 \mathrm{IgG}$-saporin injection (see also Fig. 4). $A$ and $B$, Charting of ChAT-positive basal forebrain neurons after intraventricular saline injection. Ch 1 neurons are located in the medial septum $(\mathrm{ms})$, Ch 2 neurons are located in the nucleus of the vertical limb of the diagonal band $(n v l)$, and $C h 4$ neurons are distributed in the nucleus basalis $(n b)$, sublenticular substantia innominata $(s i)$, and the nucleus ansae lenticularis ( $\mathrm{nal}$ ). $\mathrm{C}$ and $D$, Charting of ChAT-positive basal forebrain neurons in a rat after intraventricular $192 \mathrm{IgG}$-saporin injection. Note the essentially complete loss of the cholinergic neurons in the medial septum, diagonal band, and magnocellular preoptic nucleus, but the preservation of Ch 4 neurons (arrowheads) in the ventral pallidum, nucleus basalis, sublenticular substantia innominata, and nucleus ansae lenticularis. Scale bar, $1 \mathrm{~mm}$.

nonacetylcholinesterases, $0.0072 \mathrm{gm}$ of ethopropazine was added to the incubation solution. After $50-60 \mathrm{~min}$ the incubation was stopped by rinsing in $0.1 \mathrm{~m}$ Tris buffer, $\mathrm{pH} 7.6$. The sections were then soaked in a solution of $0.008 \mathrm{gm}$ of cobalt chloride in $100 \mathrm{ml}$ of Tris for $10 \mathrm{~min}$, rinsed again in the Tris buffer, and finally incubated for $10 \mathrm{~min}$ in a solution of $0.05 \mathrm{gm}$ of diaminobenzidine (DAB) in $100 \mathrm{ml}$ of Tris with $3.3 \mathrm{ml}$ of $0.3 \% \mathrm{H}_{2} \mathrm{O}_{2}$ solution added. The sections were taken through a final rinse, dehydrated, and coverslipped with permount.

Sections of selected animals were stained free floating for reduced nicotinamide-adenine dinucleotide phosphate diaphorase (NADPHd) activity according to the direct method of Scherer-Singler et al. (1983). Briefly, sections were rinsed in $0.1 \mathrm{~m}$ Tris buffer, $\mathrm{pH} 8.0$ and then incubated in a solution containing $0.8 \%$ Triton X-100, $8 \mathrm{~mm} \mathrm{~L}$-malic acid (monosodium salt), $0.5 \mathrm{~mm}$ reduced NADPII (tetrasodium salt), and $0.8 \mathrm{~mm}$ nitro blue tetrazolium in the same Tris buffer at $37^{\circ} \mathrm{C}$. The incubation was stopped after 10-15 min by rinsing in the Tris buffer and then the sections were mounted, air dried, dehydrated, and coverslipped with permount.

Immunohistochemistry. Immunohistochemical staining using a monoclonal antibody to bovine ChAT (Ab8) was carried out using the peroxidase-antiperoxidase (PAP) method of Sternberger (1986). All other immunohistochemical stains were performed following the avidinbiotin ABC procedure (Hsu et al., 1981).

The basic $\mathrm{ABC}$ immunohistochemical procedure was as follows: free-
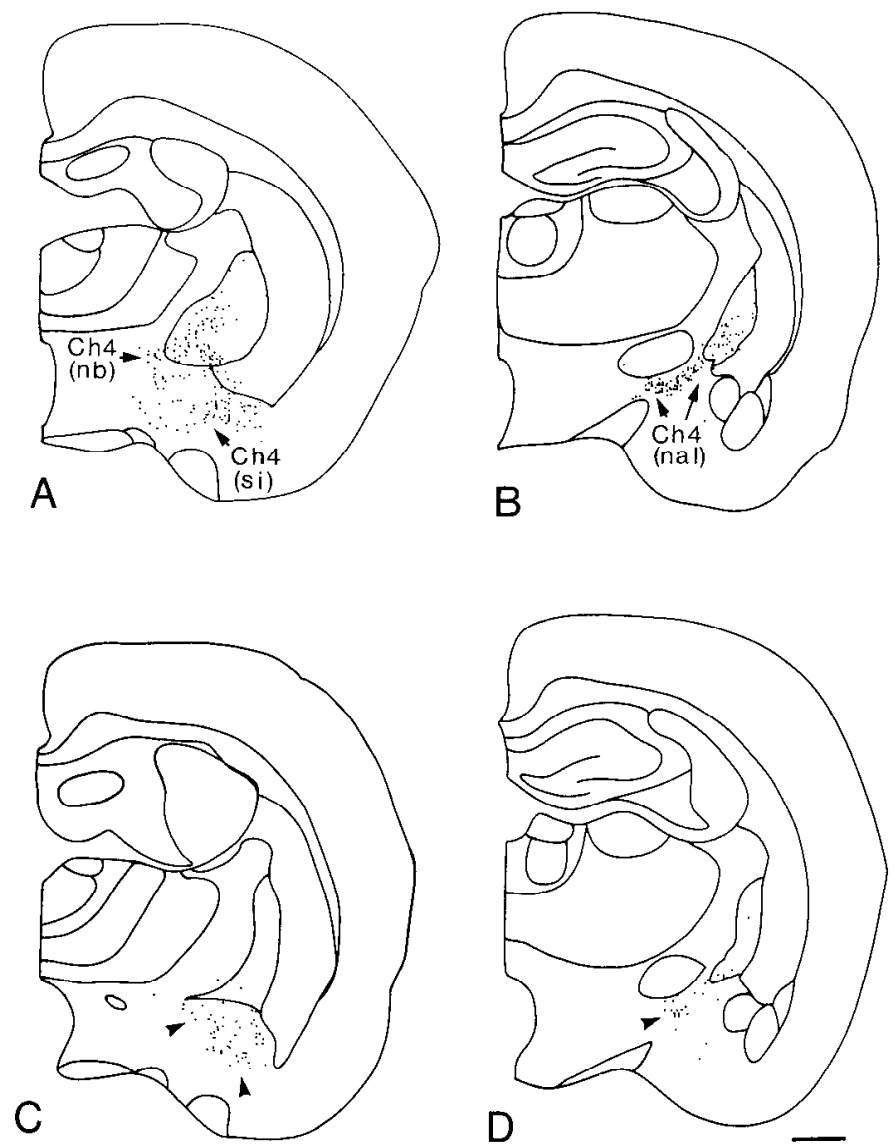

Figure 4. Distribution of ChAT-positive basal forebrain neurons in rats $22 \mathrm{~d}$ after intraventricular saline or $192 \mathrm{IgG}$-saporin injection. $A$ and $B$, ChAT-positive basal forebrain neurons after intraventricular saline injection. $C$ and $D$, ChAT-positive basal forebrain after intraventricular $192 \mathrm{IgG}$-saporin injection. For abbreviations, see Figure 3.

floating sections were rinsed in $0.1 \mathrm{M}$ phosphate-buffered saline, treated with $0.4 \%$ Triton $\mathrm{X}-100$ in PBS for $1 \mathrm{hr}$, soaked in carrier medium consisting of $3 \%$ goat serum and $0.1 \%$ Triton X-100 in PBS for $1 \mathrm{hr}$, and subsequently incubated in solutions of primary antibodies in carrier medium for $24-72 \mathrm{hr}$ at $4^{\circ} \mathrm{C}$. After rinsing, the sections were incubated in appropriate solutions of biotinylated secondary antibodies (1:500) in carrier medium for $24 \mathrm{hr}$ at $4^{\circ} \mathrm{C}$. The sections were then rinsed again and transferred to a 1:100 solution of peroxidase-labeled avidin-biotin complexes in carrier medium for $2 \mathrm{hr}$. After a final rinse in $0.05 \mathrm{M}$ Tris buffer, the sections were exposed to a solution of $0.005 \% \mathrm{DAB}$ and $0.01 \% \mathrm{H}_{2} \mathrm{O}_{2}$ in $0.05 \mathrm{M}$ Tris buffer, $\mathrm{pH} 7.6$.

Monoclonal antibodies (and their concentrations) used in the present study were directed against (1) purified p75 NGF receptors (1:500) and (2) the calcium-binding protein parvalbumin purified from carp muscle (1:2000) (Sigma Chemical Co., St. Louis, MO). Polyclonal antibodies used were directed against (1) human placental ChAT (1:1000), (2) the vitamin $\mathrm{D}-$ dependent calcium-binding protein calbindin- $\mathrm{D}_{28 \mathrm{~K}}(1: 5000)$, (3) the enzymes tyrosine hydroxylase (TH) (1:1000) and (4) dopamine$\beta$-hydroxylase (DBH) (1:1000) (both from Eugene Tech, Allendale, NJ), and (5) the neurotransmitter serotonin (5-hydroxytryptamine, 5-HT) (1:1000) (Incstar, Stillwater, MN).

In some cases, the DAB polymers were intensified using a modified Fontana-Masson method (Masson, 1928). As described by Kitt et al. (1988), the sections were incubated in a $2.5 \%$ silver nitrate solution, and then placed in a $0.2 \%$ gold chloride solution and fixed in $5 \%$ sodium. thiosulfate.

\section{Analysis}

Sections were examined using bright-field and dark-field microscopy. The extent of the cholinergic basal forebrain lesion was judged qualitatively by careful analysis of serial sections (stained for cresyl violet, $\mathrm{NGFr}, \mathrm{ChAT}$, and $\mathrm{AChE}$ ) through the entire forebrain, brainstem, and 

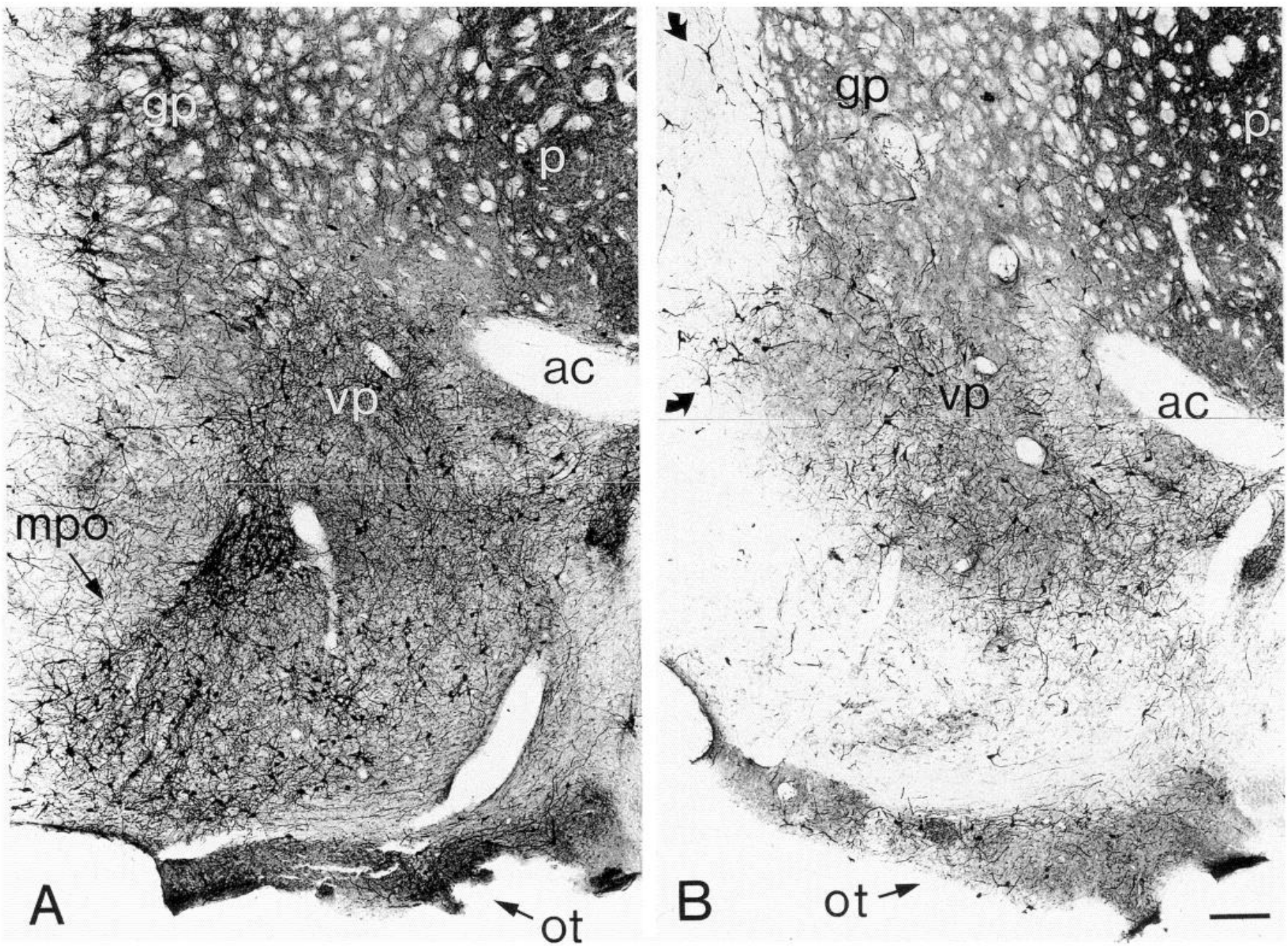

Figure 5. Differential vulnerability of closely adjacent cholinergic basal forebrain neurons after intraventricular 192 IgG-saporin injection (ChAT immunohistochemistry). $A$, ChAT-positive neurons in (from ventral to dorsal) the olfactory tubercle (ot), magnocellular preoptic nucleus ( $m p o$ ), ventral pallidum $(v p)$ below the anterior commissure $(a c)$, globus pallidus $(g p)$, and putamen $(p)$ of a rat $22 \mathrm{~d}$ after intraventricular saline injection. $B$, ChAT-positive neurons in the same structures of a rat $22 \mathrm{~d}$ after intraventricular $192 \mathrm{IgG}$-saporin injection. Note the almost complete loss of cholinergic neurons in the magnocellular preoptic nucleus, but the considerable number of spared Ch 4 cholinergic neurons in the ventral pallidum and medial aspects of the globus pallidus (curved arrows). The cholinergic neurons in putamen and olfactory tubercle are unchanged. Scale bar, $200 \mu \mathrm{m}$.

cerebellum. Selected sections were charted with the aid of a plotter connected to the movable stage of a microscope via a computer (Microplotter $4000+$, DiLog Instruments, Tallahassee, FL). The specificity of the lesion for cholinergic basal forebrain neurons was studied with serial, adjacent sections stained for NGFr, ChAT, AChE, parvalbumin, calbindin- $\mathrm{D}_{28 \mathrm{~K}}$, NADPHd, TH, and DBH. Unilateral $192 \mathrm{IgG}$-saporin injections into the substantia innominata were compared with the contralateral saline injection. Intraventricular, septal, and bilateral substantia innominata injections were compared with saline injections at the same coordinates. Cortical areas were delineated according to the classification of Zilles (Paxinos and Watson, 1986). Cholinergic neurons were classified according to the nomenclature proposed by Mesulam et al. (Mesulam et al., 1983; Rye et al., 1984).

\section{Results}

\section{General observations}

The male Sprague-Dawley rats used in the present study tolerated intraventricularly (3.36 or $4.2 \mu \mathrm{g}$ ) as well as intraparenchymally $(0.126 \mu \mathrm{g})$ injected $192 \mathrm{IgG}$-saporin. Most animals showed weight loss or a decreased weight gain in the first week after surgery. We observed no fatalities of animals that had recovered from the pentobarbital anesthesia.
How complete is the degeneration of cholinergic basal forebrain neurons?

\section{$N G F r$-positive basal forebrain neurons}

The strong perikaryal immunoreactivity for the p75 NGF receptor in the cholinergic basal forebrain neurons was unchanged after intraventricular or intraparenchymal saline injections (Fig. $1 A-C)$. In these animals, a dense network of NGFr-positive fibers could be observed in target areas of the cholinergic basal forebrain neurons, including the entire cortical mantle and the hippocampus (Fig. $2 A, B$ ), as well as parts of the amygdala. NGFr immunoreactivity was unaltered in rats after intraparenchymal injections of only the $192 \mathrm{IgG}$ antibody into the substantia innominata (data not shown).

$192 \mathrm{IgG}$-saporin injections into the ventricle induced an almost complete and bilateral loss of perikaryal NGFr immunoreactivity in the basal forebrain (Fig. $1 D-F$ ). Some sections displayed two or three residual NGFr-positive neurons in the basal forebrain (Fig. 1D). No NGFr-positive axonal staining was seen in cortex, hippocampus (Fig. $2 C, D$ ), or amygdala. 

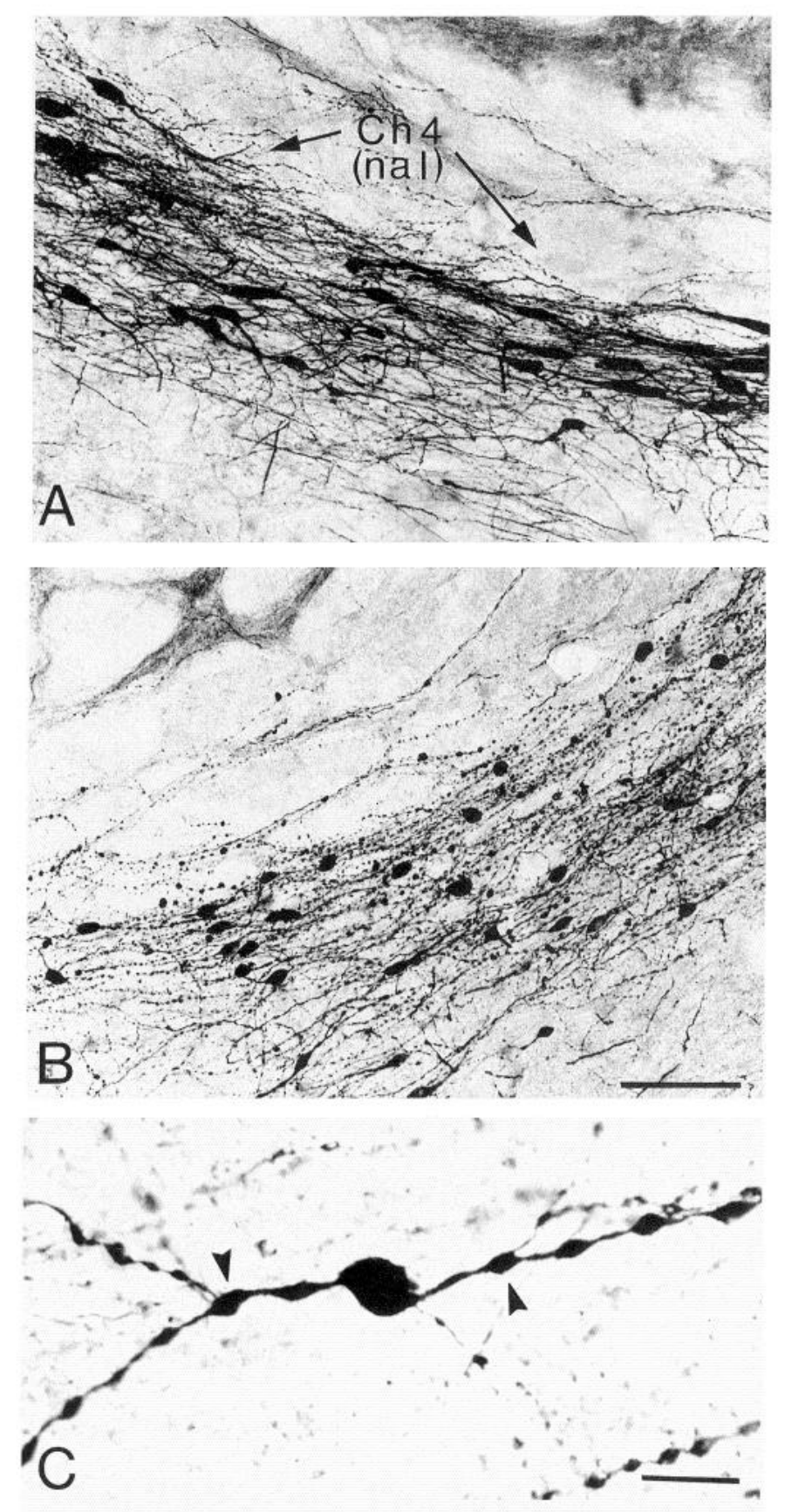

Figure 6. Early signs of degeneration in Ch 4 neurons (ChAT immunohistochemistry). ChAT-positive neurons of the posterior Ch 4 group (nucleus ansae lenticularis) display a normal morphology $5 \mathrm{~d}$ after local injection of $192 \mathrm{IgG}$-saporin into the anterior $\mathrm{Ch} 4$ group on the contralateral side $(A)$, but show signs of degeneration ipsilaterally $(B)$. Axons as well as dendrites contribute to the large number of beaded neurites (arrowheads in $C$ ). Scale bars: $A, 100 \mu \mathrm{m}$ for $A$ and $B ; C, 10$ $\mu \mathrm{m}$.

Intraparenchymal 192 IgG-saporin injections induced a more restricted loss of NGFr-positive basal forebrain neurons. (1) Single septal area injections produced a complete and bilateral loss of NGFr-positive septal neurons as well as considerable bilateral loss of NGFr-positive neurons in the diagonal band of Broca. Virtually all NGFr-positive neurons in the nucleus basalis-substantia innominata complex were unchanged. (2) Unilateral substantia innominata injections produced a complete loss of NGFr-positive neurons in the ipsilateral substantia innominata and also widespread loss of ipsilateral NGFr-positive neurons of the diagonal band. Very little loss of NGFr-positive neurons was seen in the septal area. (3) Bilateral substantia innominata injections $(2 \times 0.3 \mu \mathrm{l})$ also reduced the number of NGFr-positive septal neurons.

The loss of NGFr immunoreactivity in the somata was matched by a loss of NGFr-positive fibers in the respective target areas, that is, in the hippocampus after septal injections and in the cortex and amygdala after substantia innominata injections.

Time course. A complete loss of NGFr-positive basal forebrain neurons was seen as early as $2 \mathrm{~d}$ after $192 \mathrm{IgG}$-saporin injection. This was unchanged over the course of $180 \mathrm{~d}$.

\section{ChAT-positive basal forebrain neurons}

The extensive collection of cholinergic basal forebrain neurons was unaltered after intraventricular or intraparenchymal saline injection (Figs. $3 A, B ; 4 A, B$ ).

Intraventricular 192 IgG-saporin injections induced a widespread loss of ChAT-positive basal forebrain neurons (Figs. $3 C, D$; $4 C, D)$. This reduction was essentially complete in the $\mathrm{Ch} 1$ [medial septum (ms)], Ch 2 [vertical limb of diagonal band of Broca (nvl)], and Ch 3 (horizontal limb of diagonal band of Broca) groups of cholinergic neurons and in the magnocellular preoptic nucleus (mpo) (Figs. 3-5). Many sectors of the Ch 4 group, however [i.e., cholinergic neurons in the nucleus basalis of Meynert (nb), ventral pallidum (vp), sublenticular substantia innominata (si), and the nucleus ansae lenticularis (nal)], displayed a considerable number of residual ChAT-positive neurons (Figs. $3 D ; 4 C, D ; 5 B$ ). For example, the ventral pallidum displayed surviving cholinergic neurons, whereas almost all cholinergic neurons in the directly adjacent magnocellular preoptic nucleus were lost (Figs. $3 D, 4 C, 5 B$ ). Intraparenchymal injections displayed the same degree of selective damage: complete loss of $\mathrm{Ch} 1$ and 2 neurons after septal injections and incomplete loss of Ch 4 neurons after substantia innominata injections.

Time course. The loss of ChAT-positive basal forebrain neurons was first seen $2 \mathrm{~d}$ after $192 \mathrm{IgG}$-saporin injection into the substantia innominata and gradually increased over the next 5 d(Fig. 6). The extent of the lesion and the distribution of residual cholinergic neurons as described above were observed mainly in animals killed after $22 \mathrm{~d}$ (Figs. 3, 4). The pattern remained unchanged in animals $180 \mathrm{~d}$ after $192 \mathrm{IgG}$-saporin injection.

\section{AChE-positive fibers}

The histochemical reaction product for AChE can be used as a marker for cholinergic fibers in the rat cortex with the exception of a few cortical areas, such as the retrosplenial cortex and somatosensory barrel fields (Lysakowski et al., 1989). Target areas of the cholinergic basal forebrain neurons, such as the hippocampus, the olfactory bulb, the cortex, and the amygdala, displayed a high density of AChE-positive fibers (Figs. 7 $\mathrm{A} ; 8 \mathrm{~A}-$ $C ; 9 A, B)$. This pattern was unchanged after saline injection.

Intraventricular injection of $192 \mathrm{IgG}$-saporin. The olfactory bulb, the projection target for the $\mathrm{Ch} 3$ group, showed a complete loss of AChE-positive fibers (Fig. 8D). The hippocampus and cingulate cortex, recipients of cholinergic fibers from the $\mathrm{Ch} 1$ and $\mathrm{Ch} 2$ group, displayed a complete loss of AChE-positive fibers (Figs. 7, 8E). A dense band of AChE activity, observed in the retrosplenial cortex of control rats (Figs. $7 A, 8 C$ ), did not disappear after $192 \mathrm{IgG}$-saporin injection (Figs. $7 B, 8 F$ ). Frontal, temporal, parietal, and occipital isocortex, innervated by 


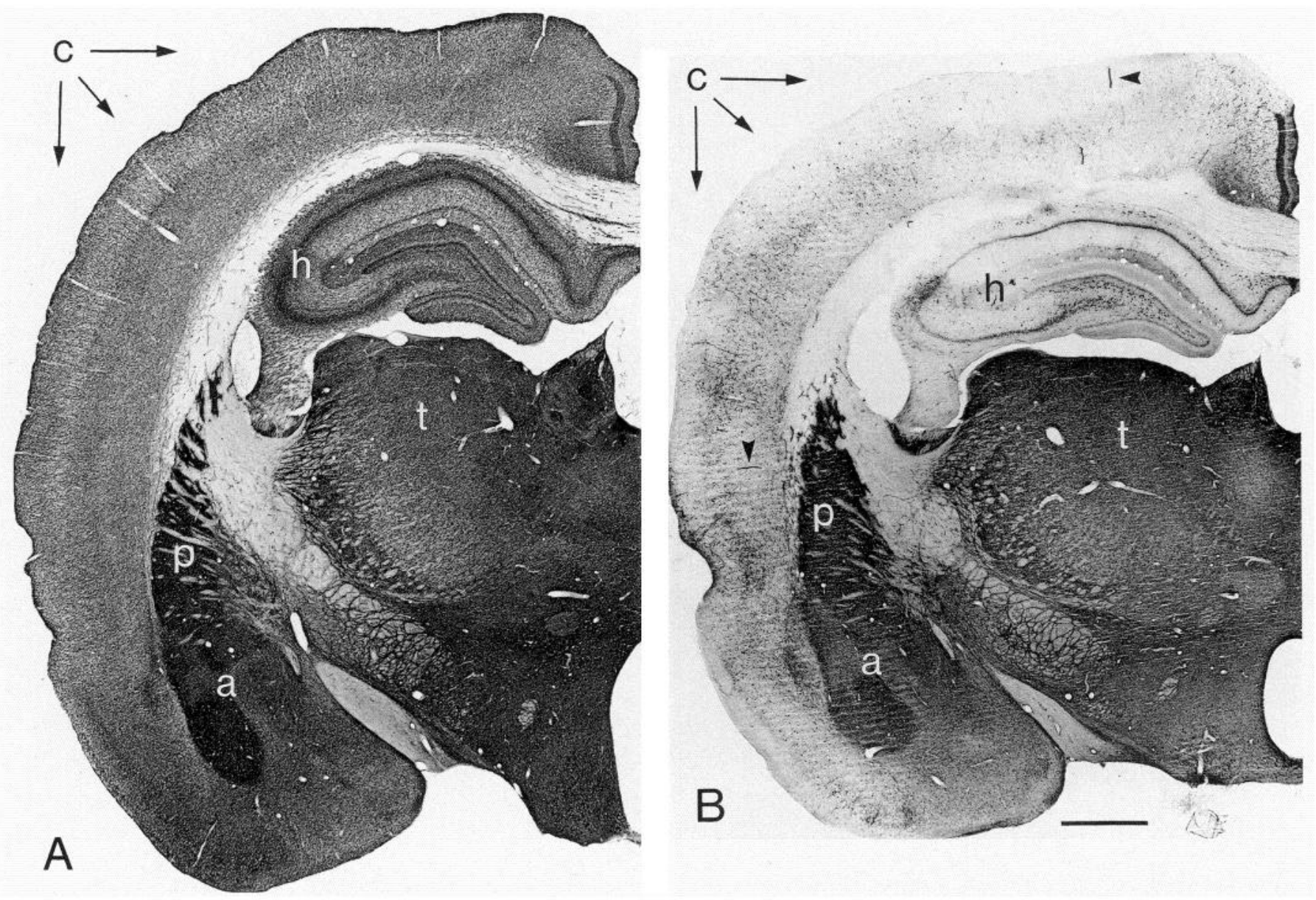

Figure 7. Extent of cholinergic deafferentiation after intraventricular 192 IgG-saporin injection (AChE histochemistry). The dense network of AChE-positive fibers in the cortex $(c)$ and hippocampus $(h)$ of a saline-treated rat $(A)$ has almost completely disappeared $22 \mathrm{~d}$ after intraventricular $192 \mathrm{IgG}$-saporin injection $(B)$. Arrowheads in $B$ point to large vessels. The dense AChE reaction product in the amygdala $(a)$, putamen $(p)$, and thalamus $(t)$ are unchanged $(A, B)$. Scale bar, $1 \mathrm{~mm}$.

the Ch 4 group, displayed an almost complete loss of AChEpositive fibers (Fig. $7 B$ ). Paralimbic cortical areas (insular cortex, perirhinal cortex, piriform cortex, and entorhinal cortex), which are also innervated by the $\mathrm{Ch} 4$ group, displayed only a partial loss of AChE-positive fibers (Fig. 9C). AChE-positive fibers in the amygdala, a target area of cholinergic neurons of the Ch 4 group, were essentially unchanged 3 weeks after 192 IgG-saporin injection (Figs. 7B, 9D).

The lesioned animals in which ChAT-positive cortical and hippocampal fibers could be visualized confirmed the pattern of cholinergic denervation as seen with AChE histochemistry. The upper layer 3 of the retrosplenial cortex displays a band of much stronger $\mathrm{AChE}$ activity than the adjacent layers 2 and lower layer 3 (Figs. 7; 8C,F). ChAT-positive fibers, however, are much denser in layers 2 and lower layer 3 (data not shown). Therefore, we considered the band of strong AChE activity in the upper layer 3 of the retrosplenial cortex to be noncholinergic.

Intraparenchymal injection of $192 \mathrm{IgG}$-saporin. Septal injections induced a complete loss of AChE-positive fibers in the entire hippocampus and in medial and directly adjacent cortical areas (cingulate cortex, retrosplenial cortex, frontal cortex, forelimb and hindlimb areas, and occipital cortex). Bilateral substantia innominata injections induced the same degree of neocortical deafferentiation as the intraventricular injections and produced only mild to moderate loss of AChE-positive fibers in the hippocampus. The AChE-positive innervation of the basolateral nucleus of the amygdala and the nucleus of the lateral olfactory tract was essentially unchanged, whereas the remaining amygdaloid nuclei showed some loss of AChE-positive fibers.

Comparison to excitatory amino acid lesions. Injections of 192 IgG-saporin into the substantia innominata reduced the density of AChE-positive fibers in the cortex more completely than ibotenic acid and quisqualic acid injections (Fig. 10). 192 IgG-saporin injections caused a depletion of AChE-positive fibers throughout the neocortical mantle, whereas excitatory amino acids caused a more restricted depletion, probably confined to the cortical projection areas of the cholinergic neurons around the injection site.

Time course. This pattern of AChE-positive fiber loss, observed in animals $22 \mathrm{~d}$ after lesioning, developed gradually over the first $5 \mathrm{~d}$ after $192 \mathrm{IgG}$-saporin injection into the substantia innominata. It was essentially unchanged $180 \mathrm{~d}$ after 192 IgGsaporin injections into the ventricle or the substantia innominata.

How specific is the lesion for basal forebrain cholinergic neurons?

NGFr-positive structures outside the basal forebrain

All structures expressing the 75 NGF receptor can be expected to be affected by $192 \mathrm{IgG}$-saporin injections. We studied the 

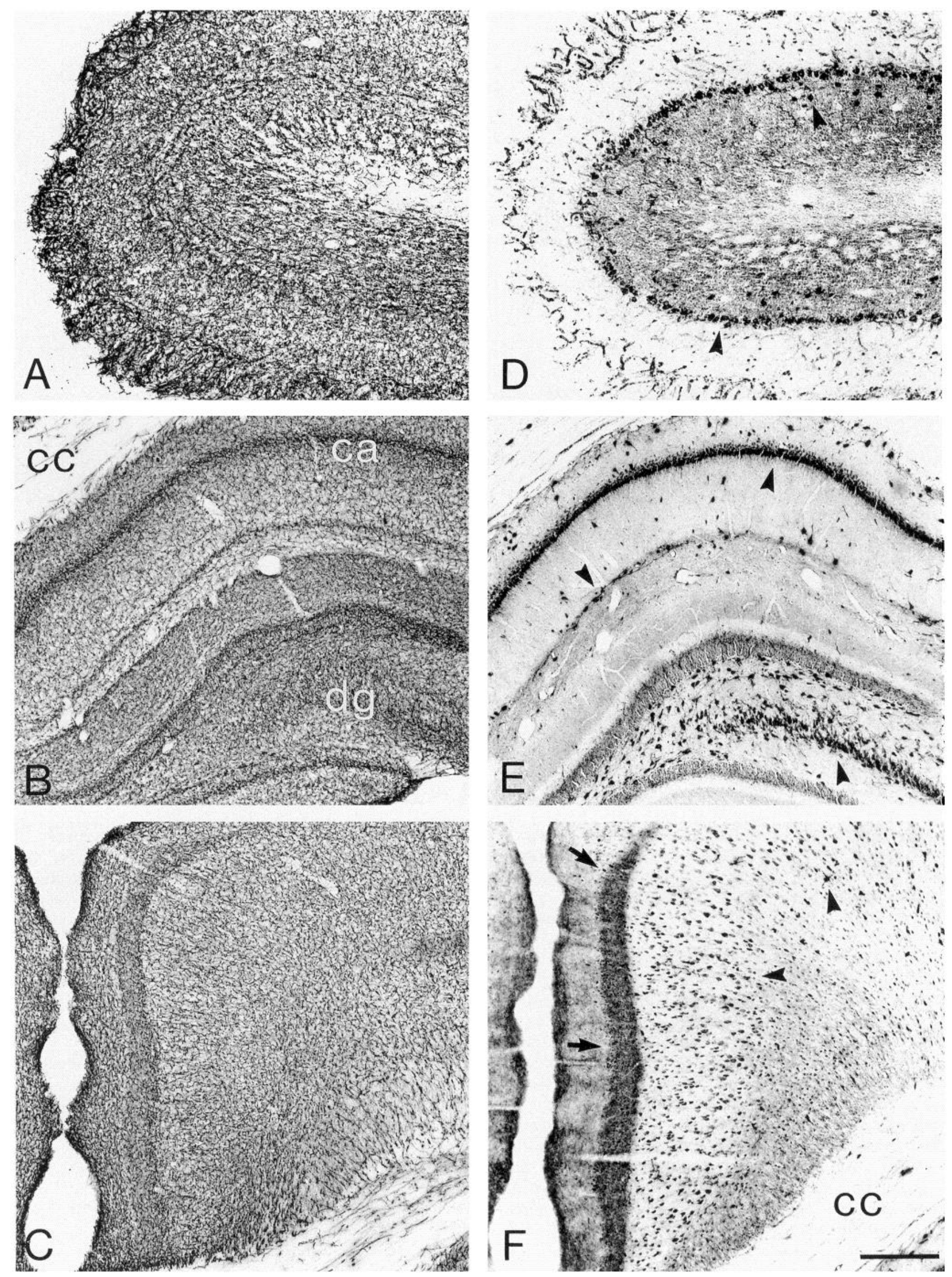

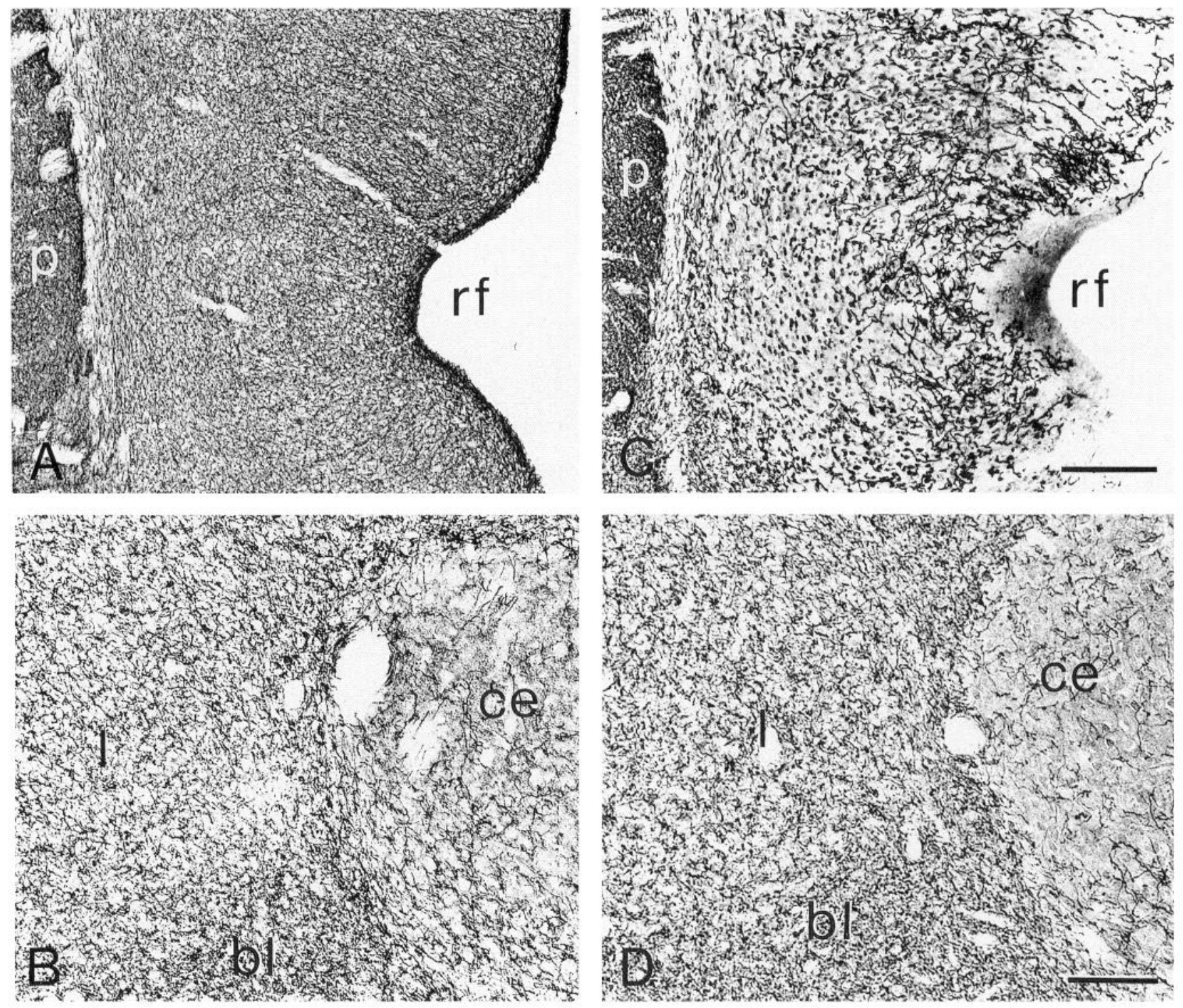

Figure 9. Preservation of AChE-positive fibers in target areas of cholinergic basal forebrain neurons (AChE histochemistry). $A$ and $B$, The caudal insular cortex between putamen $(p)$ and the rhinal fissure $(r f)(A)$ and the amygdala $(B)$ display a high density of AChE-positive fibers in a salinetreated rat. $C$ and $D$, The insula shows some preserved AChE-positive fibers $22 \mathrm{~d}$ after intraventricular $192 \mathrm{IgG}$-saporin injection $(C)$. The dense collection of AChE-positive fibers in the basolateral $(b l)$ and lateral $(l)$ nuclei and the low density of AChE-positive fibers in the central nucleus (ce) of the amygdala are essentially unchanged $22 \mathrm{~d}$ after intraventricular $192 \mathrm{IgG}$-saporin injection $(D)$. Scale bars: $C, 300 \mu \mathrm{m}$ for $A$ and $C ; D$, $100 \mu \mathrm{m}$ for $B$ and $D$.

effect on four different structures outside the basal forebrain that either revealed NGFr immunoreactivity in our material or for which such evidence is reported in the literature (Pioro and Cuello, 1988, 1990b; Altar, 1991): the mesencephalic trigeminal nucleus, the raphe nuclei in the medulla oblongata, the Purkinje cells of the cerebellum, and the cholinergic neurons of the neostriatum.

The mesencephalic trigeminal nucleus displayed the highest level of NGFr immunoreactivity outside the basal forebrain. This pattern was not affected by $192 \mathrm{IgG}$-saporin injections into the ventricle or intraparenchymally into the substantia innominata and septal nuclei (Fig. 11A).

The raphe nuclei, reported to express low levels of NGFr immunoreactivity in the adult rat brain (Pioro and Cuello, 1990a), did not show prominent staining in our material. In sections stained for 5-HT, no difference could be observed comparing control animals with animals after intraventricular 192 IgG-saporin injections (Fig. 11B).

The cerebellar Purkinje cells displayed characteristic bands of NGFr staining (Fig. 12A). Purkinje cells were also visualized

Figure 8. Complete loss of AChE-positive fibers in target areas of cholinergic basal forebrain neurons (AChE histochemistry). The dense collection of AChE-positive fibers in the olfactory bulb $(A)$, the cornu ammonis $(\mathrm{ca})$ and dentate gyrus $(\mathrm{dg})$ of the hippocampus $(B)$, and the retrosplenial cortex $(C)$ is completely lost $22 \mathrm{~d}$ after $192 \mathrm{IgG}$-saporin injection into the ventricle $(D-F)$. Note the abundance of darkly stained AChE-positive neurons in the denervated areas (arrowheads in $D-F)$. The dense AChE-positive band in upper layer 3 of the retrosplenial cortex $(C)$ is not affected by the complete loss of cholinergic afferents (arrows in F). Scale bar, $300 \mu \mathrm{m}$. 

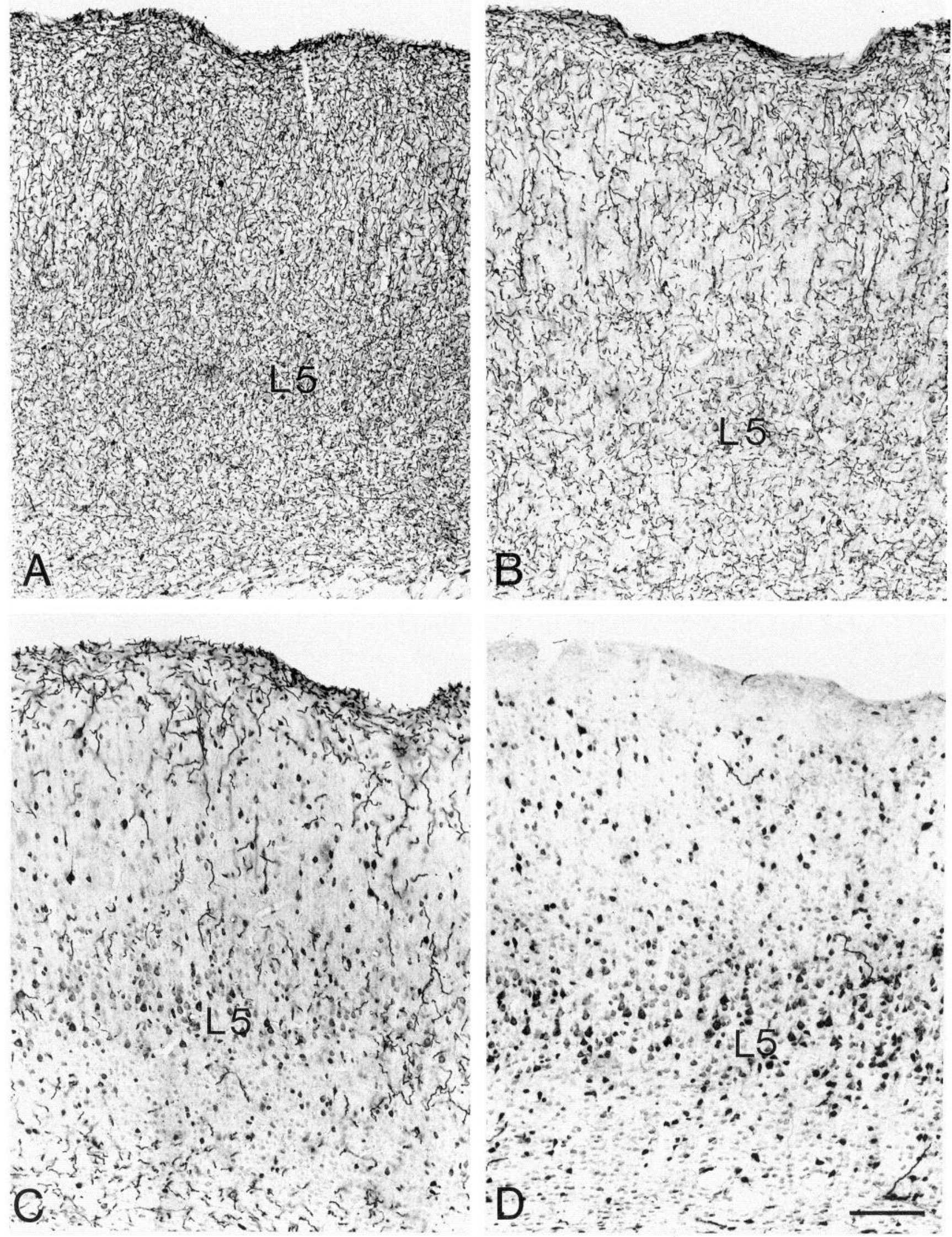
by using the calcium-binding protein calbindin- $\mathrm{D}_{28 \mathrm{~K}}$, which is expressed in Purkinje cells of normal rats (Fig. 12B). After intraventricular 192 IgG-saporin injections, no residual NGFr staining could be observed in the cerebellum (Fig. 12C). Intraventricular 192 IgG-saporin injections induced an almost complete loss of calbindin- $\mathrm{D}_{28 \mathrm{~K}}$ immunoreactivity in the dorsalmost folium and a band-like loss of immunoreactivity in more ventral folia (Fig. 12D). Careful analysis of Nissl-stained sections revealed a loss of Purkinje cells in exactly those bands of lost calbindin- $\mathrm{D}_{28 \mathrm{~K}}$ immunoreactivity. Injections of $192 \mathrm{IgG}$-saporin into the septal area or the substantia innominata did not change the calbindin- $\mathrm{D}_{28 \mathrm{~K}}$ immunoreactivity in the cerebellum.

We did not observe NGFr immunoreactivity in the neostriatum of the adult rat. Rats followed for up to $180 \mathrm{~d}$ after intraventricular $192 \mathrm{IgG}$-saporin injections showed neither signs of degeneration in Nissl-stained material nor a loss of ChATpositive striatal neurons. However, in rats that had received 192 IgG-saporin injections into the substantia innominata, a significant loss of ChAT-positive striatal interneurons could be observed. This was especially pronounced in cases followed for $180 \mathrm{~d}$ after injection (Fig. 13). This loss of cholinergic striatal interneurons seemed to be specific, since striatal NADPHdpositive neurons were not affected by ventricularly or parenchymally injected 192 IgG-saporin (data not shown).

\section{NGFr-negative structures}

We studied three neuronal populations of special interest with regard to the specificity of a cholinergic basal forebrain lesion after $192 \mathrm{IgG}$-saporin injection: (1) ChAT-positive structures outside the basal forebrain, (2) noncholinergic basal forebrain neurons, and (3) noncholinergic cell groups diffusely projecting to the cortex.

ChAT-positive neurons in cortex, epithalamus, and brainstem. A subpopulation of cortical interneurons expressed ChAT immunoreactivity in the adult rat brain. These neurons did not express NGFr immunoreactivity and were not affected after 192 IgG-saporin injections (Fig. 14A).

Cholinergic neurons of the pedunculopontine nucleus (Ch 5 group), the laterodorsal tegmental nucleus (Ch 6 group), and the medial habenula (Ch 7 group) did not display NGFr staining and were unaffected by $192 \mathrm{IgG}$-saporin injections (Fig. 14B,C). The same was true for the ChAT-positive motor nuclei of the pons and medulla oblongata (motor trigeminal nucleus, dorsal motor vagal nucleus, facial nucleus, hypoglossal nucleus).

Noncholinergic basal forebrain neurons. Cholinergic neurons in the medial septum and diagonal band of Broca are adjacent to noncholinergic neurons expressing the calcium-binding protein parvalbumin (Fig. 15A,B). Intraventricular injections of $192 \mathrm{IgG}$-saporin, which induced a complete loss of cholinergic neurons in the septum, did not change the immunoreactivity for parvalbumin in these midline septal neurons (Fig. 15C,D).

Cholinergic neurons of the $\mathrm{Ch} 3$ and $\mathrm{Ch} 4$ groups are adjacent to noncholinergic neurons expressing the calcium-binding protein calbindin- ${ }_{28 \mathrm{~K}}$ (Fig. 16A,B). $192 \mathrm{IgG}$-saporin injections into the ventricle, which induced a widespread loss of $\mathrm{Ch} 3$ and $\mathrm{Ch}$

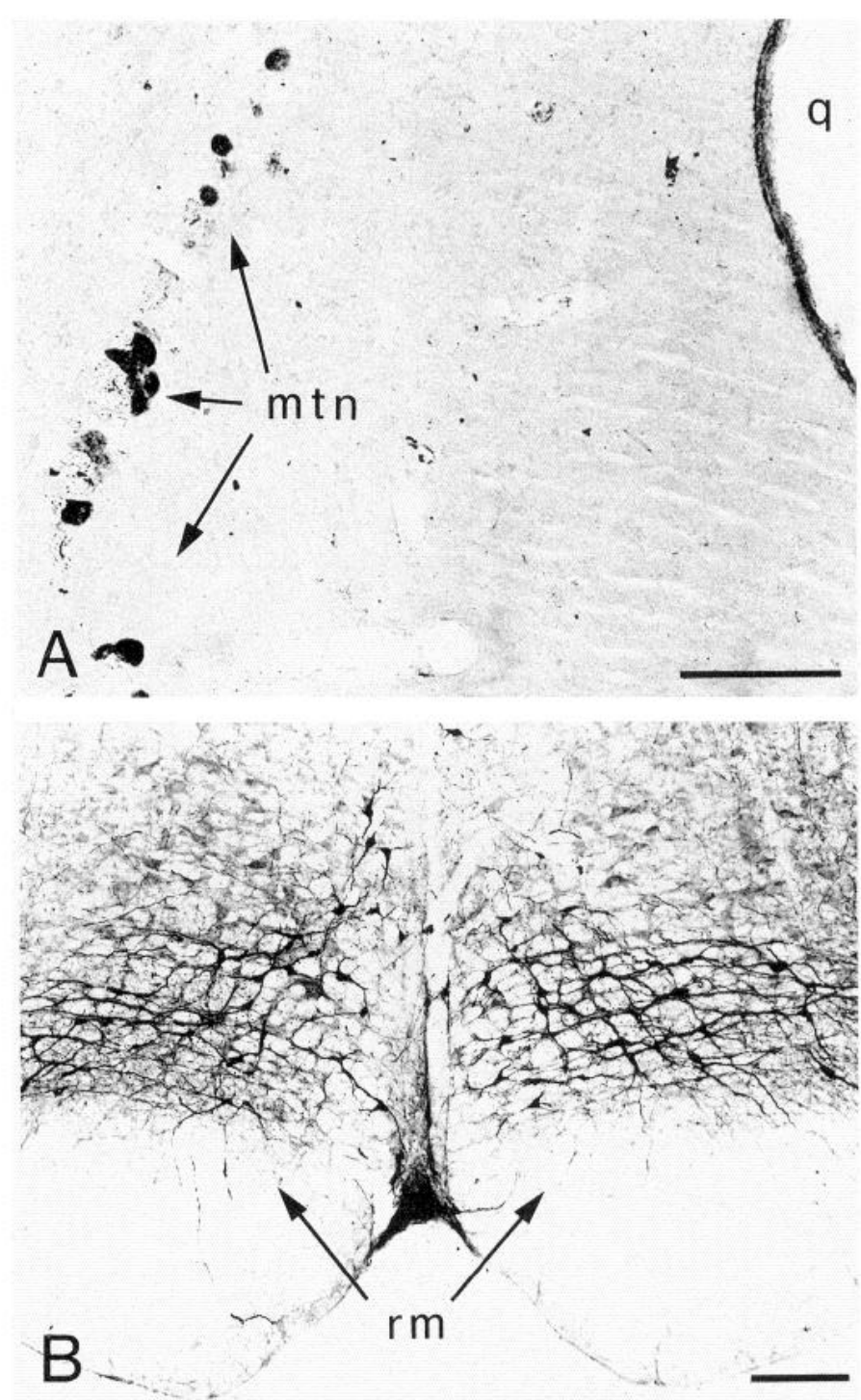

Figure 11. Preservation of NGFr-expressing neurons outside the basal forebrain. $A$, The NGFr immunoreactivity of the mesencephalic nucleus of the trigeminal nerve $(m t n)$ is unaltered after intraventricular $192 \mathrm{IgG}$ saporin injection; $q$ indicates cerebral aqueduct. $B$, Serotonergic neurons of the raphe magnus nucleus $(\mathrm{rm})$ display a normal level of 5-HT immunoreactivity after intraventricular $192 \mathrm{IgG}$-saporin injection. Scale bars, $200 \mu \mathrm{m}$.

4 neurons, did not change the immunoreactivity for calbindin$\mathrm{D}_{28 \mathrm{~K}}$ in adjacent noncholinergic neurons (Fig. 16C,D).

The majority of neurons in the medial septum and vertical limb of the diagonal band that express NADPHd activity are cholinergic. In the horizontal limb of the diagonal band and the substantia innominata, however, many NADPHd-positive neurons do not express ChAT immunoreactivity. A normal distribution of NADPHd-positive neurons was found after intraventricular $192 \mathrm{IgG}$-saporin injections in areas devoid of any ChAT-positive Ch 3 or $\mathrm{Ch} 4$ neurons (data not shown).

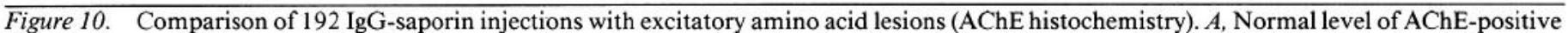

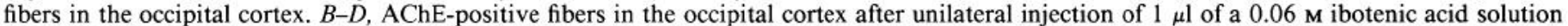

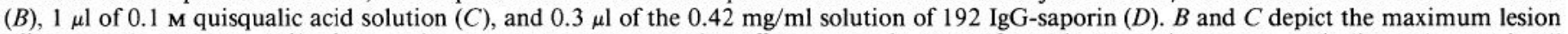

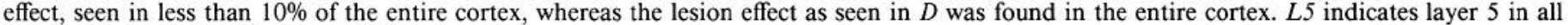
four cortical samples. Scale bar, $200 \mu \mathrm{m}$. 


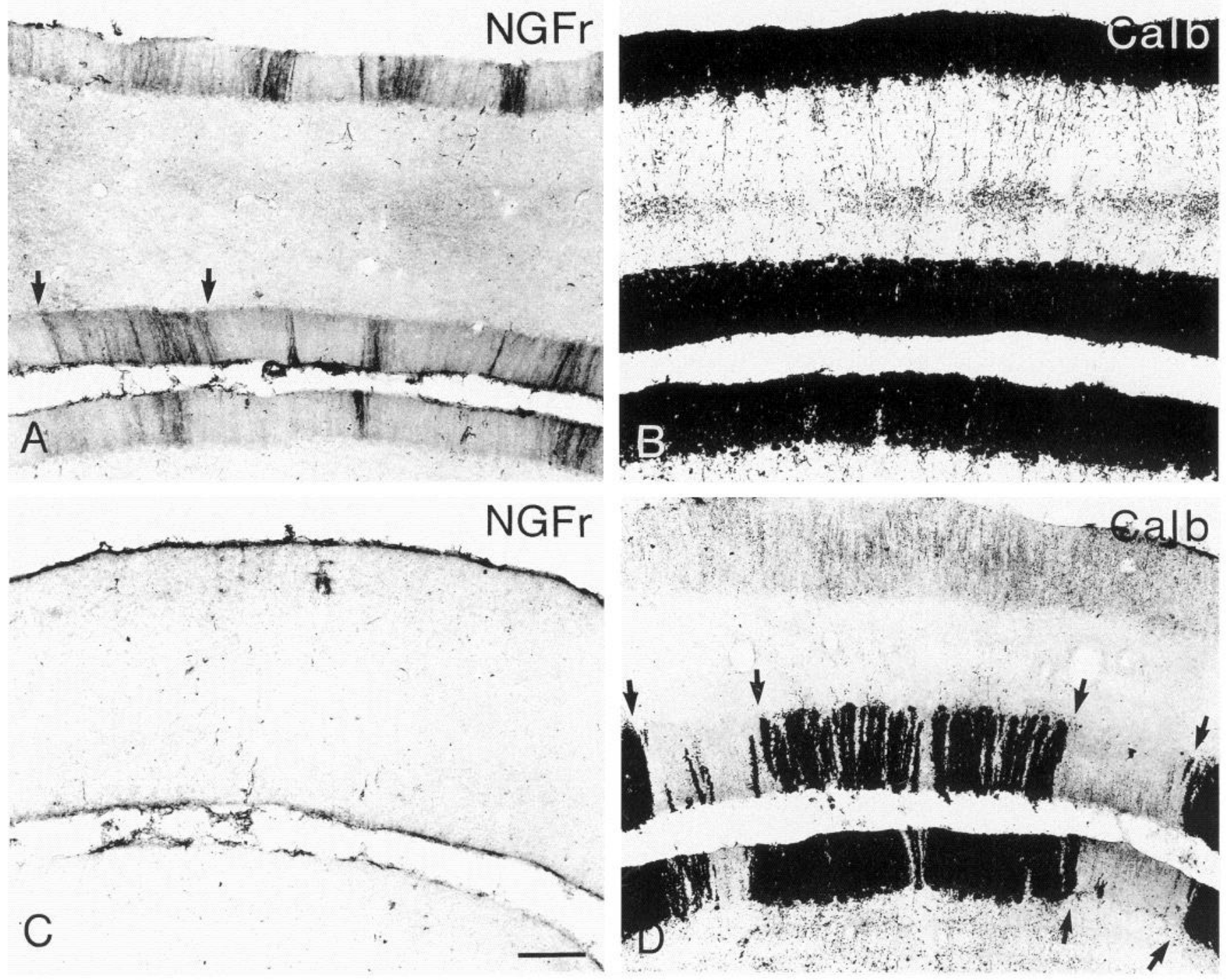

Figure 12. Loss of cerebellar Purkinje cells after intraventricular $192 \mathrm{IgG}$-saporin injection. $A$, Saline-treated rats display a low level of NGFr immunoreactivity in Purkinje cell perikarya and their dendrites in the adjacent molecular layer. Note the characteristic band-like accentuation of NGFr immunoreactivity (arrows). B, All Purkinje cells in saline-treated rats displayed high levels of calbindin- $D_{28 \mathrm{~K}}$ immunoreactivity. $C$, No NGFr immunoreactivity was seen in the Purkinje cells after intraventricular 192 IgG-saporin injection. $D$, The pronounced loss of Purkinje cells after $192 \mathrm{IgG}$-saporin injection was clearly seen with an antibody against calbindin- $\mathrm{D}_{28 \mathrm{~K}}$. Note the complete loss in the dorsalmost folium and the bandlike loss in the more ventral folia (arrows). Scale bar, $200 \mu \mathrm{m}$.

The distribution of parvalbumin-, calbindin- $\mathrm{D}_{28 \mathrm{~K}}{ }^{-}$, and NADPHd-positive basal forebrain neurons was also studied in rats after injection of $192 \mathrm{IgG}$-saporin into the septal area or the substantia innominata. Tissue damage due to the needle tract and high background immunoreactivity precluded an analysis of parvalbumin- and calbindin-positive neurons in the immediate vicinity of the injection site. Nissl-stained sections revealed a stronger gliotic reaction around the injection site compared to intraventricular 192 IgG-saporin injections. However, in all cases studied, numerous parvalbumin-positive septal and diagonal band neurons as well as calbindin- $\mathrm{D}_{28 \mathrm{~K}^{-}}$and NADPHd-positive neurons in the nucleus basalis-substantia innominata complex were observed in areas totally devoid of ChAT- and NGFr-positive basal forebrain neurons.

DBH-positive and TH-positive neurons. Dopaminergic and noradrenergic neurons were assessed by using antibodies against TH and DBH (Fig. 17). Animals followed up to $22 \mathrm{~d}$ after intraventricular or intraparenchymal injections of 192 IgG-sap- orin did not show changes of perikaryal immunoreactivity or in the dense noradrenergic and dopaminergic innervation of cortical areas that had been depleted of cholinergic fibers (Fig. $17 B, D)$.

How does the toxin-coupled antibody reach its target?

We injected a mixture of $192 \mathrm{IgG}$-saporin $(1.68 \mu \mathrm{g})$ and colchicine $(2 \mu \mathrm{g})(n=2)$ or just $192 \mathrm{IgG}$-saporin $(1.68 \mu \mathrm{g})(n=1)$ into the ventricle of three animals. The colchicine/192 IgGsaporin-treated rats showed normal fiber density over the entire cortex contralateral to the injection site (Fig. 18A) and some fiber loss ipsilaterally. The animal injected with only 192 IgGsaporin showed complete bilateral loss of AChE-positive fibers in isocortex and hippocampus (Fig. 18B).

\section{Discussion}

Our study addresses the extent, selectivity, and specificity of the cholinergic denervation induced by the immunotoxin 192 IgG- 


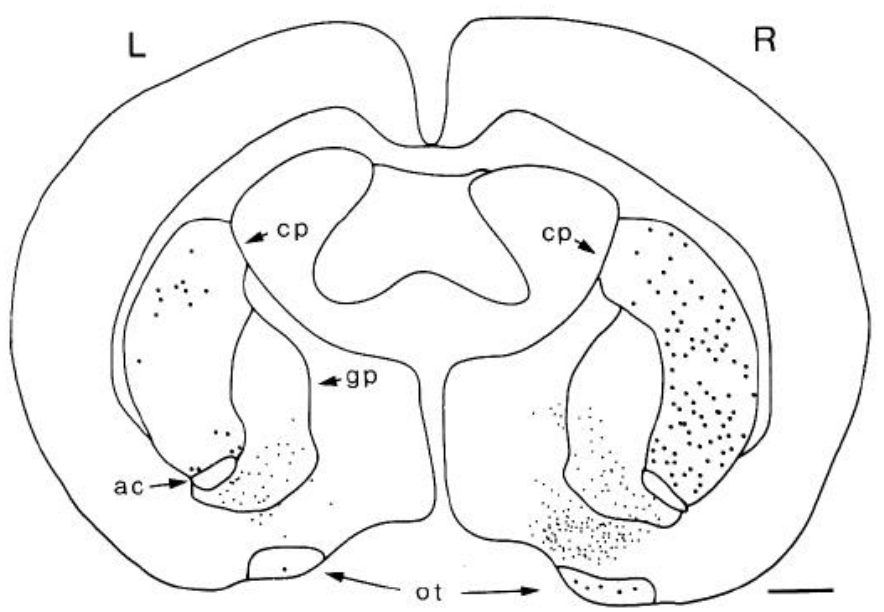

Figure 13. Loss of cholinergic striatal interneurons after 192 IgGsaporin injection into the basal forebrain. Six months after unilateral 192 IgG-saporin injection into the left basal forebrain, the ChAT-positive neurons (large dots) in the ipsilateral caudate-putamen $(c p)$ and olfactory tubercle $(o t)$ are significantly reduced compared to the contralateral side, which received a saline injection. Note the preservation of cholinergic neurons (small dots) in ventral parts of the globus pallidus $(g p)$. This section is not near the injection site. Scale bar, $1 \mathrm{~mm}$.

saporin in the adult rat brain. Intraventricular and intraparenchymal injections induced a complete loss of NGFr-positive cholinergic neurons projecting to the neocortex and hippocampus. NGFr-negative cholinergic neurons of the nucleus basalissubstantia innominata complex were not affected. 192 IgG-saporin proved to be relatively specific for NGFr-positive cholinergic basal forebrain neurons since noncholinergic basal forebrain neurons, noncholinergic cortical afferents, and cholinergic neuronal groups outside the basal forebrain were preserved. However, two neuronal groups outside the basal forebrain that express the p75 NGF receptor, cerebellar Purkinje cells and cholinergic striatal interneurons, were vulnerable to injury by 192 IgG-saporin.

\section{Extent of cholinergic basal forebrain lesions}

In previous studies, mechanical lesions or local injections of neurotoxins into the basal forebrain produced an incomplete cholinergic deafferentiation of cortex and hippocampus (for review, see Olton and Wenk, 1987; Smith, 1988; Dekker et al., 1991; Dunnett et al., 1991; Reine and Nieoullon, 1992). This is in line with our experiments and those of others (Robbins et al., 1989) demonstrating that injections of various concentrations of ibotenic acid or quiqualic acid into the substantia innominata do not induce a complete loss of AChE-positive fibers in cortex and hippocampus. The more complete cholinergic denervation after intraparenchymal $192 \mathrm{IgG}$-saporin injections could be due to uptake by local collaterals and retrograde transport into the other neurons of the Ch $1-4$ complex. For example, injections into the substantia innominata always reached all NGFr-positive $\mathrm{Ch} 4$ neurons in the nucleus basalis-substantia innominata complex and also spread to the Ch 1-3 neurons.

Intraventricular injections reached virtually every cholinergic basal forebrain neuron that expressed the p 75 NGF receptor. This seems to be mediated by terminal uptake and retrograde transport to the soma as demonstrated by the protection of NGFr-positive basal forebrain neurons by simultaneous injec-
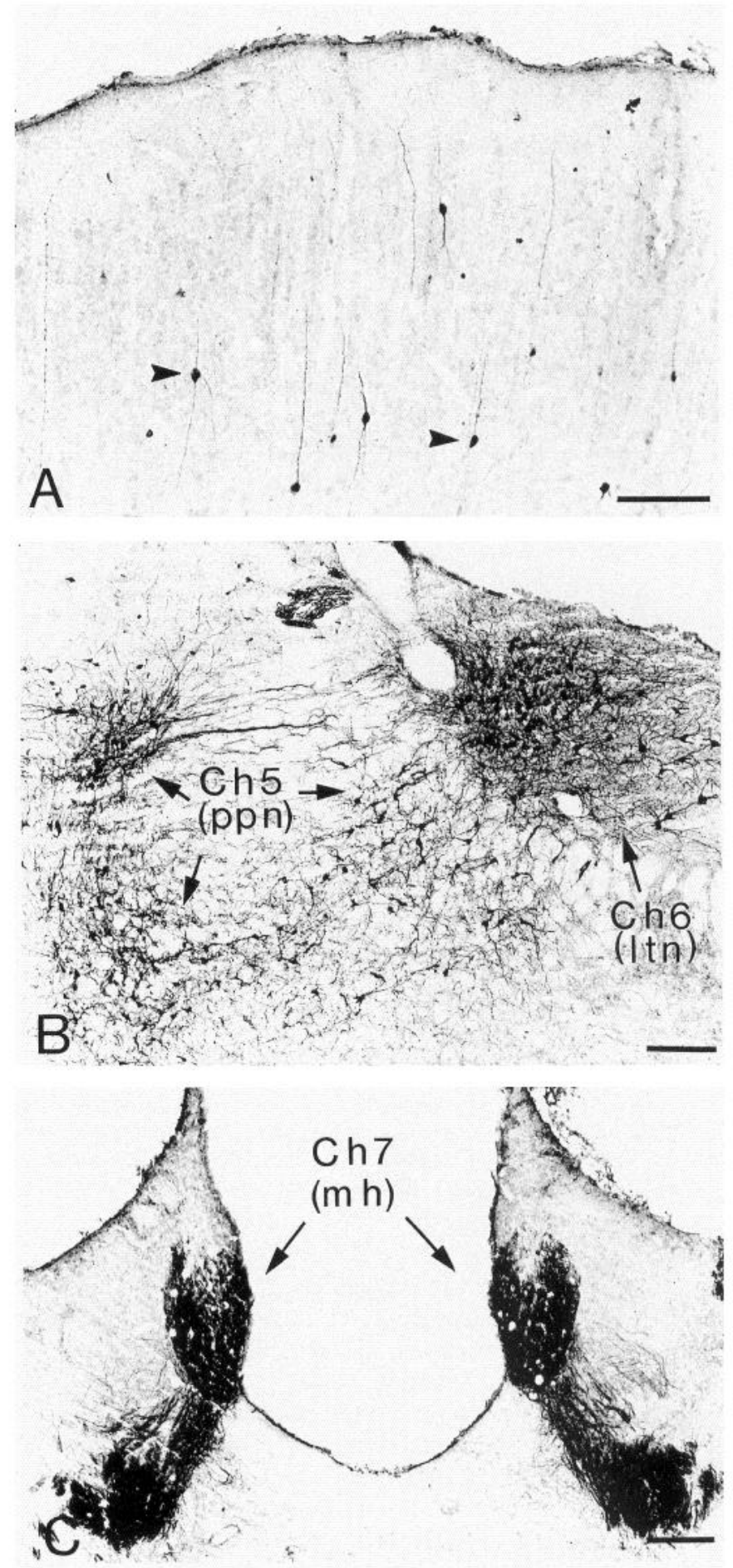

Figure 14. Preservation of ChAT-positive neurons in cortex, brainstem, and thalamus. $A$, Cortical interneurons expressing ChAT immunoreactivity (arrowheads) are unaltered after intraventricular 192 $\mathrm{IgG}$-saporin injection. $B$, Cholinergic neurons in the pedunculopontine (ppn, Ch5) and laterodorsal tegmental (ltn, Ch6) nuclei display normal levels of ChAT immunoreactivity after intraventricular $192 \mathrm{IgG}$-saporin injection. $\mathrm{C}$, Cholinergic neurons in the medial habenula $(\mathrm{mh}, \mathrm{Ch} 7)$ are not affected by an intraventricular $192 \mathrm{IgG}$-saporin injection. Scale bars, $100 \mu \mathrm{m}$. 

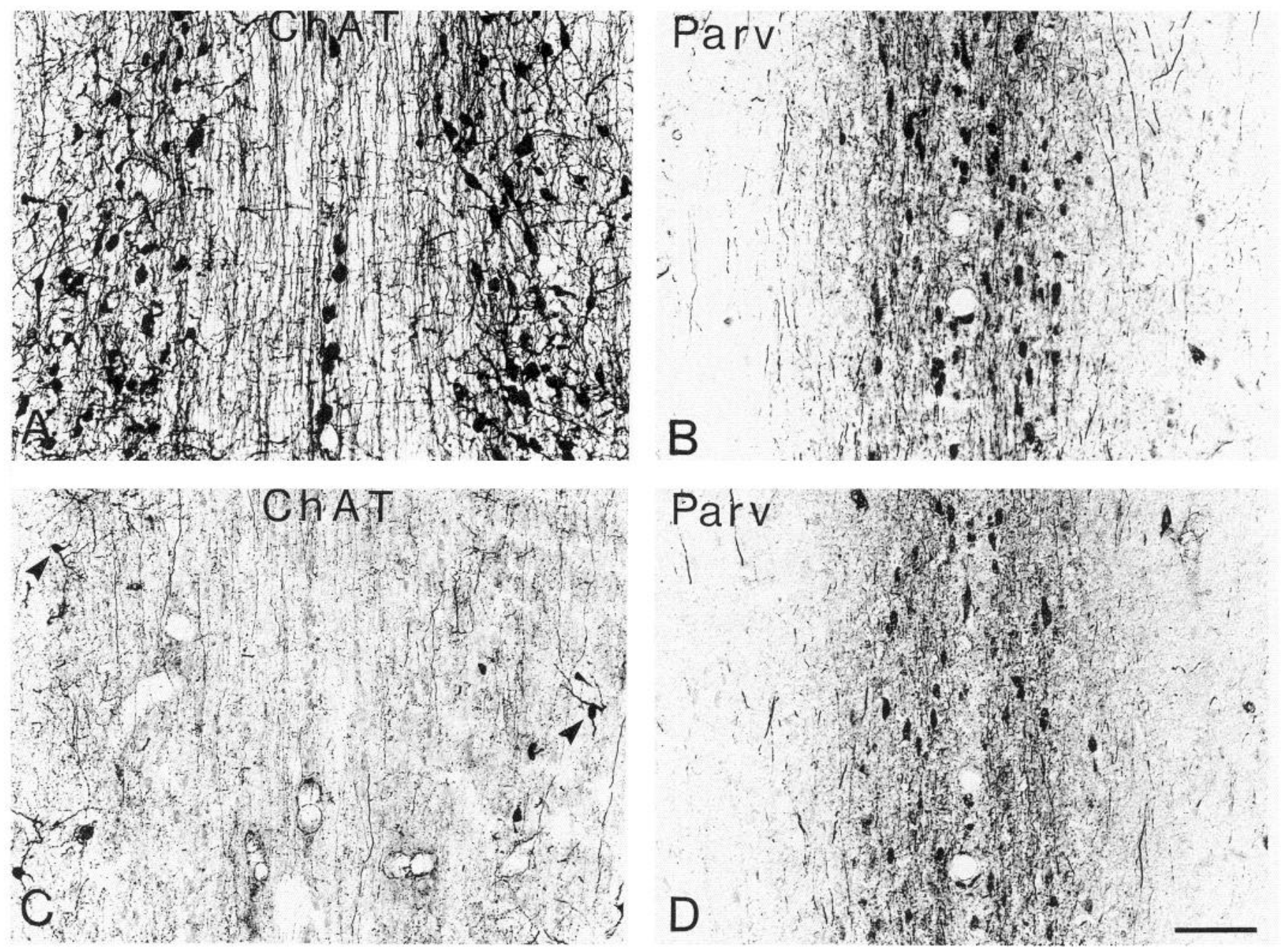

Figure 15. Specificity of damage to Ch 1 neurons after intraventricular 192 IgG-saporin injection. A, Distribution of ChAT-positive neurons in the medial septum of a saline-treated rat. $B$, In the same animal, parvalbumin-positive neurons of the medial septum are located primarily in the midline. $C$, Almost complete loss of ChAT-positive medial septum neurons (arrowheads) $22 \mathrm{~d}$ after intraventricular $192 \mathrm{IgG}$-saporin injection. $D$, In the same animal, the parvalbumin-positive neurons of the medial septum are spared by the $192 \mathrm{IgG}$-saporin injection. Scale bar, $100 \mu \mathrm{m}$.

tion of $192 \mathrm{IgG}$-saporin and colchicine. Interestingly, the NGFrpositive mesencephalic trigeminal nucleus, which sends fibers to facial and ocular muscles, was not affected by intracerebral injections of $192 \mathrm{IgG}$-saporin.

Several studies have reported a reemergence of cortical ChATlevels after basal forebrain lesions (see Table 4 in Dekker et al., 1991). This was interpreted as collateral compensatory sprouting of residual cholinergic fibers after partial lesion of the cholinergic basal forebrain neurons (Olton and Wenk, 1987). Anatomical studies have provided evidence for (Gage et al., 1983) and against (Mufson et al., 1987; Batchelor et al., 1989; Henderson, 1991) such a compensatory process. In keeping with the findings of Mufson et al. (1987), we did not observe any recovery of cholinergic fibers. This may be due to the extensive lesion of cholinergic basal forebrain neurons.

We observed an extensive number of AChE-positive cortical neurons after 192 IgG-saporin injections. Furthermore, the number of ChAT-positive cortical interneurons was unchanged after complete cholinergic denervation. This supports the suggestion that the residual ChAT and AChE activity seen in biochemical assays of cortical samples after extensive basal fore- brain lesions is due, at least in part, to intrinsic cortical neurons (Olton and Wenk, 1987; Book et al., 1992; Nilsson et al., 1992).

\section{Heterogeneity of cholinergic basal forebrain neurons}

Although injections of $192 \mathrm{IgG}$-saporin into the ventricle or the substantia innominata induced a complete loss of neocortical cholinergic fibers, a considerable number of cholinergic neurons and limbic cholinergic fibers were not affected. These neurons did not express the p75 NGF receptor and were localized mainly in the ventral pallidum and ventral to the lenticular nucleus (sublenticular substantia innominata according to Carlsen et al., 1985). Previous studies have demonstrated such a population of ChAT-positive, NGFr-negative neurons in the nucleus basalis-substantia innominata complex of the rat (Dawbarn et al., 1988; Kiss et al., 1988; Batchelor et al., 1989; Woolf et al., 1989; Bickel and Kewitz, 1990). It is very likely that those residual ChAT-positive, NGFr-negative neurons give rise to the dense cholinergic innervation of the amygdala and parts of the rhinal paralimbic areas that were spared or only partially affected by 192 IgG-saporin injections (S. Heckers and M.-M. Mesulam, unpublished observation). This is in accordance with studies on 

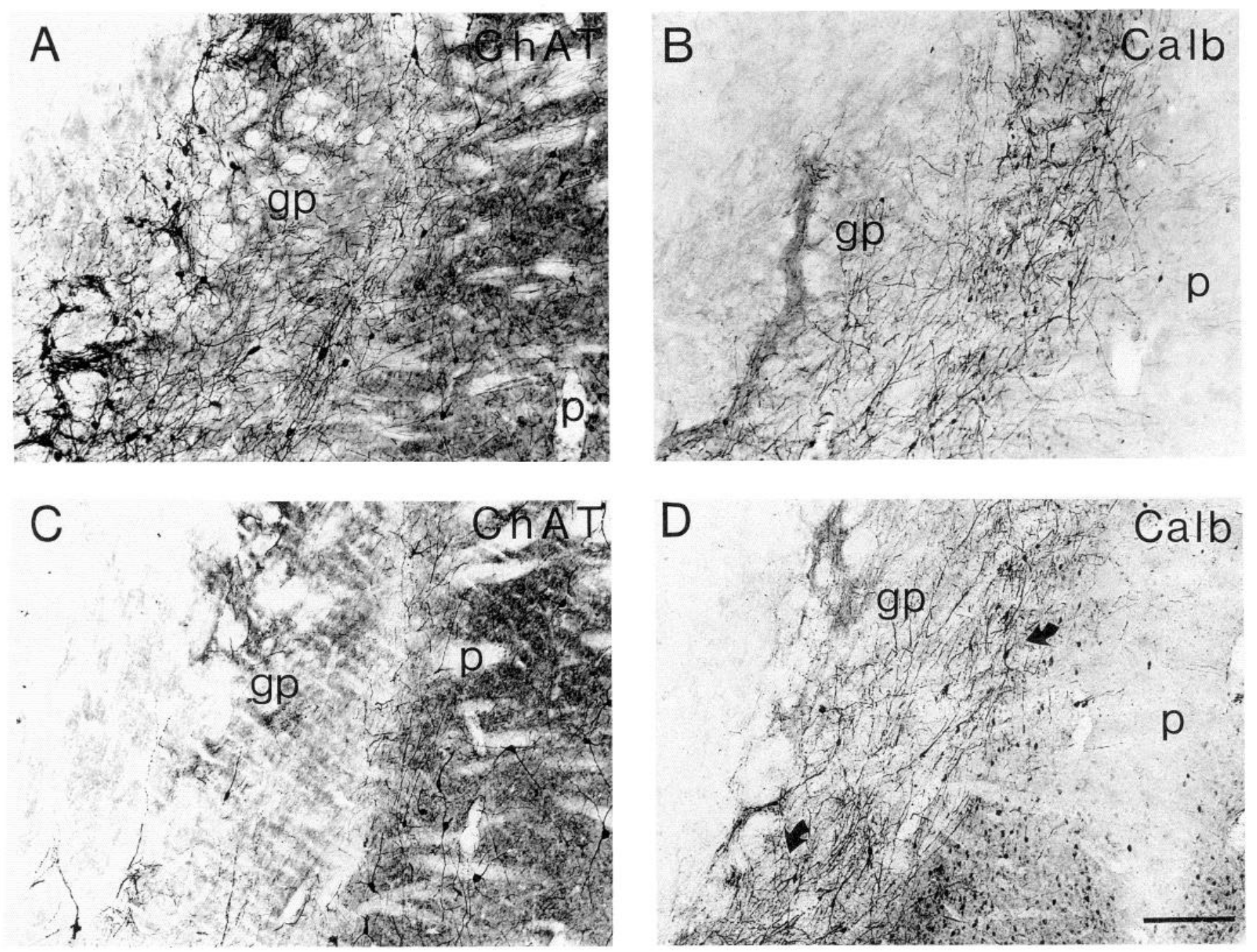

Figure 16. Specificity of damage to $\mathrm{Ch} 4$ neurons after intraventricular $192 \mathrm{IgG}$-saporin injection. $A$, Saline-treated rats display ChAT-positive neurons in the putamen $(p)$ and two compartments of the $\mathrm{Ch} 4$ complex, medial to the globus pallidus $(\mathrm{g} p)$ and in the medullary stria, interspersed between putamen and globus pallidus. $B$, In the same animal, small perikarya and fibers immunoreactive for calbindin- $\mathrm{D}_{28 \mathrm{~K}}$ are located in the medullary stria and adjacent putamen. $C$, Twenty-two days after intraventricular $192 \mathrm{IgG}$-saporin injection, the cholinergic neurons in the putamen are unchanged, whereas almost all $\mathrm{Ch} 4$ neurons are lost. $D$, In the same animal, the calbindin- $\mathrm{D}_{28 \mathrm{~K}}$-positive neurons (curved arrows) are unchanged. Scale bar, $200 \mu \mathrm{m}$.

the basal forebrain afferents to the amygdala in the rat (Nagai et al., 1982; Woolf and Butcher, 1982; Carlsen et al., 1985; Luiten et al., 1985, 1987; Rao et al., 1987; Henderson and Evans, 1991). It is of interest that the heterogeneity of cholinergic neurons in the nucleus basalis-substantia innominata complex with regard to $\mathrm{p} 75 \mathrm{NGF}$ receptors coincides with a clear distinction in the projection pattern of these two groups of neurons. It is not clear whether such a correlation exists for other heterogeneous chemical markers of rat basal forebrain neurons such as galanin or NADPHd (Pasqualotto and Vincent, 1991; Geula et al., 1993). However, there seems to be a differential vulnerability of cholinergic basal forebrain neurons to excitatory amino acids. For example, Boegmann et al. (1992) demonstrated that $\alpha$-amino-3-hydroxy-4-isoxazole propionic acid (AMPA) and quisqualic acid injections into the nucleus basalis reduce ChAT activity primarily in the cortex whereas quinolinic acid and ibotenic acid injections reduce ChAT activity primarily in the amygdala. This might be due to the differential expression of glutamate receptor types on cholinergic basal forebrain neurons projecting to the amygdala or the cortex. Such a heterogeneity could explain why AMPA and quisqualic acid injections, which leave cholinergic neurons projecting to the amygdala relatively intact, produce only marginal impairments in cognitive tasks that are significantly impaired after ibotenic acid injections (Dunnett et al., 1991; Boegmann et al., 1992).

\section{Specificity of cholinergic basal forebrain lesions}

Our experiments demonstrate that 192 IgG-saporin spares three groups of noncholinergic and one group of cholinergic basal forebrain neurons: (1) parvalbumin-positive, presumably GABAergic (Freund, 1989) septal neurons that are intermingled with cholinergic neurons of the $\mathrm{Ch} 1$ and $\mathrm{Ch} 2$ group (Alonso et al., 1990; Kiss et al., 1990a,b; Brauer et al., 1991), (2) neurons that express immunoreactivity for the calcium-binding protein calbindin- $\mathrm{D}_{28 \mathrm{~K}}$ and that are adjacent to the $\mathrm{Ch} 4$ neurons (Chang and Kuo, 1991; Geula et al., 1993), (3) substantia innominata neurons with NADPH-diaphorase activity that are mostly non- 

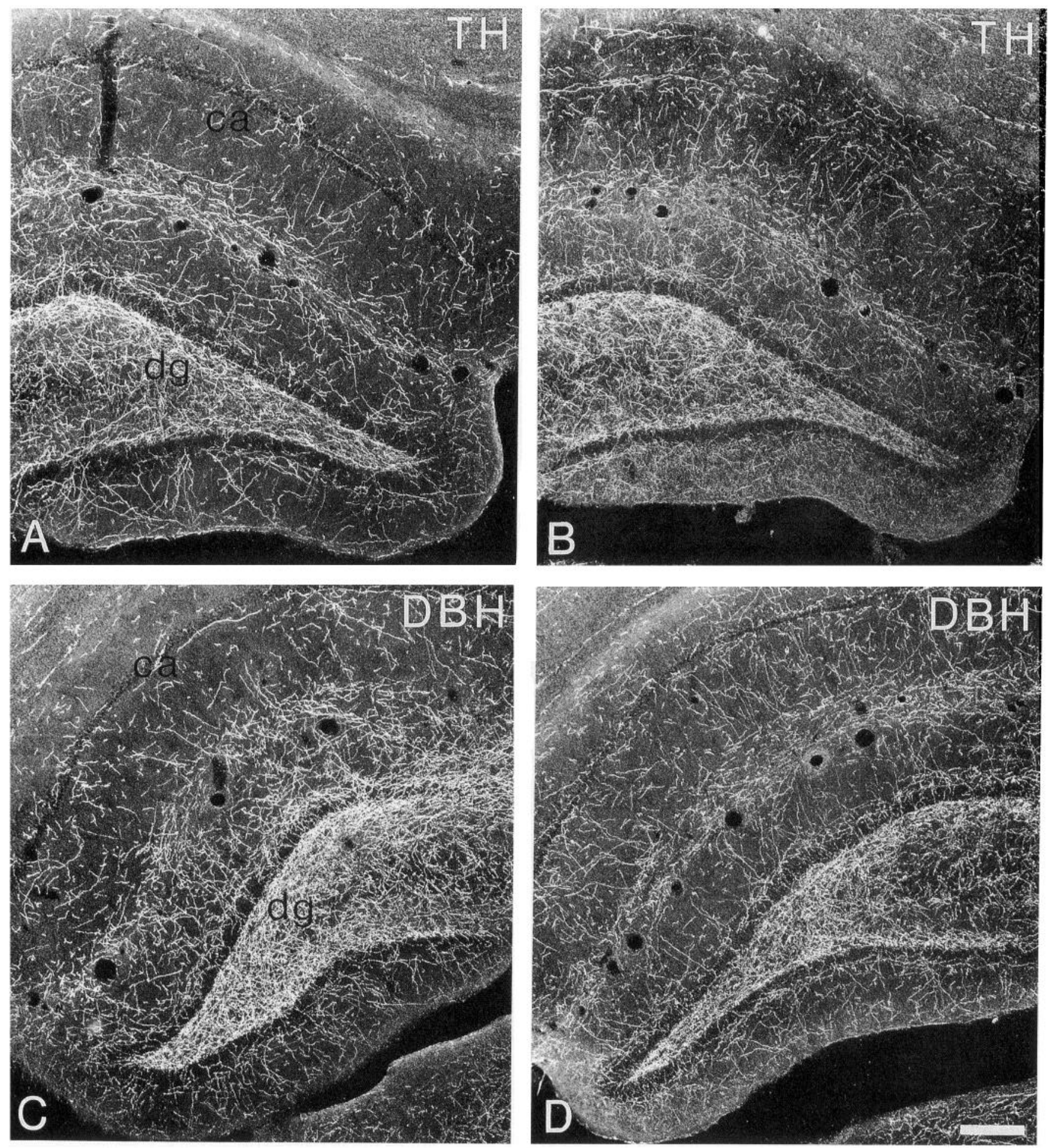

Figure 17. Preservation of TH- and DBH-positive hippocampal afferents after intraventricular 192 IgG-saporin injection. $A$ and $B$, No consistent change was found comparing tyrosine hydroxylase $(T H)$-positive fibers in dentate gyrus and cornu ammonis of rats $22 \mathrm{~d}$ after intraventricular saline injection $(A)$ or $192 \mathrm{IgG}$-saporin injection $(B)$. $C$ and $D$, No consistent change was seen in the density of dopamine- $\beta$-hydroxylase $(D B H)$ positive fibers in animals $22 \mathrm{~d}$ after intraventricular saline $(C)$ or $192 \mathrm{IgG}$-saporin $(D)$ injection. Scale bar, $200 \mu \mathrm{m}$.

cholinergic (Pasqualotto and Vincent, 1991; Geula et al., 1993), and (4) NGFr-negative, ChAT-positive neurons of the Ch 4 group. Our analysis of these four groups of spared neurons was based on a qualitative comparison of serial sections through the entire forebrain. Although we did not observe any neuronal shrinkage or neuronal loss in any of these noncholinergic neuronal groups comparing $192 \mathrm{IgG}$-saporin injections with saline injections, we cannot exclude relatively small quantitative differences in perikaryal size or neuronal density.

Parenchymal 192 IgG-saporin injections induced a more pro- 

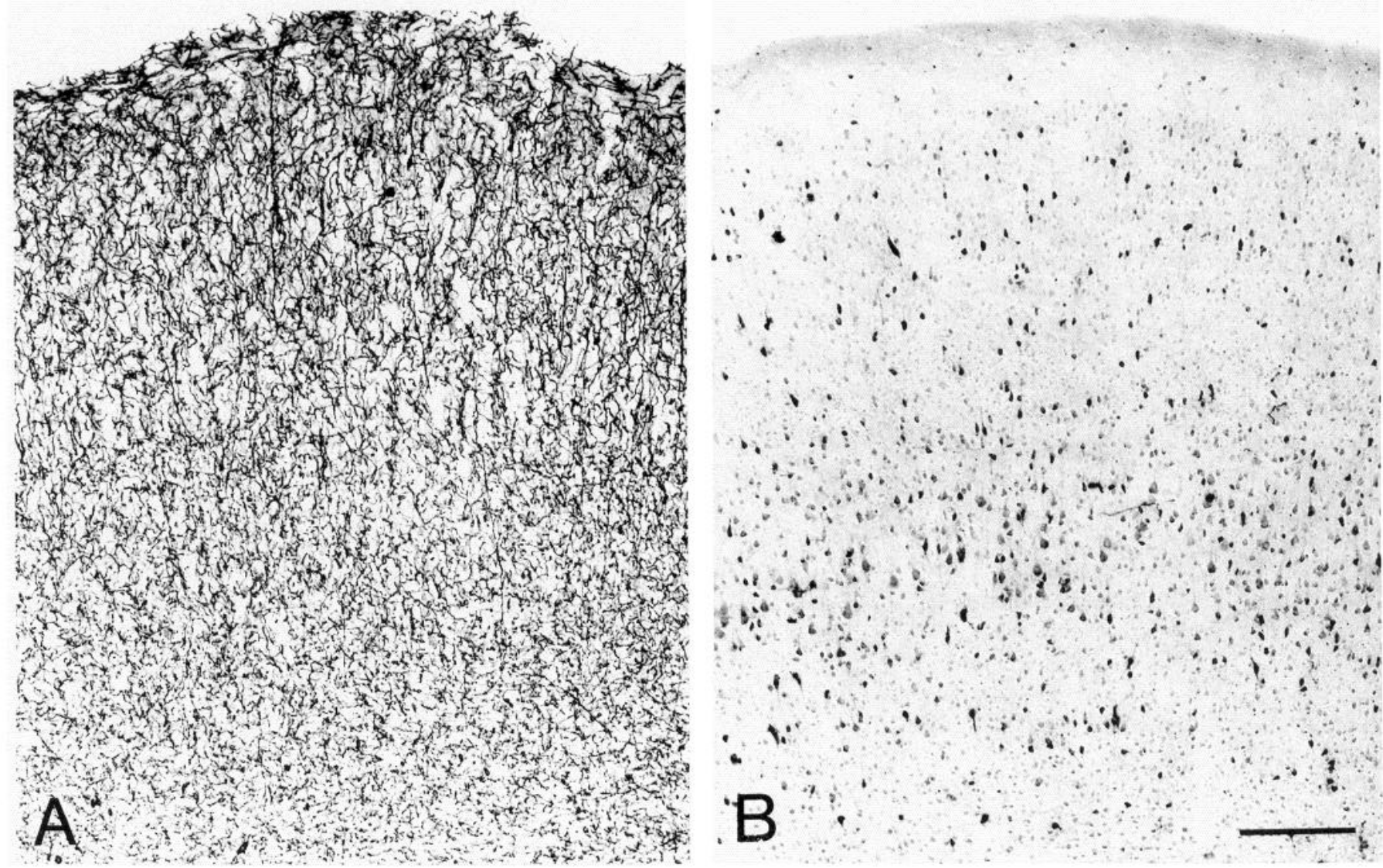

Figure 18. Colchicine blocks the $192 \mathrm{IgG}$-saporin-induced loss of AChE-positive fibers. $A$, No significant loss of AChE-positive fibers in the parietal cortex of an animal $7 \mathrm{~d}$ after injection of $4 \mu \mathrm{l}$ of $192 \mathrm{IgG}$-saporin $(0.42 \mathrm{mg} / \mathrm{ml})$ mixed with $4 \mu \mathrm{l}$ of colchicine $(0.5 \mathrm{mg} / \mathrm{ml})$ into the ventricle of the contralateral hemisphere. $B$, Complete loss of AChE-positive fibers in the parietal cortex $7 \mathrm{~d}$ after injection of only $4 \mu \mathrm{l}$ of $192 \mathrm{IgG}$-saporin $(0.42 \mathrm{mg} / \mathrm{ml})$ into the ventricle of the contralateral hemisphere. Scale bar, $200 \mu \mathrm{m}$.

nounced gliosis than intraventricular injections. Because of the gliosis and increased background immunoreactivity we could not ascertain that the noncholinergic neurons were as completely preserved after parenchymal injections as after intraventricular injections. Furthermore, substantia innominata injections also led to damage of striatal cholinergic neurons. Thus, the specificity of the lesion for cholinergic basal forebrain neurons may be less after parenchymal than intraventricular $192 \mathrm{IgG}$-saporin injection.

In the rat brain, the p $75 \mathrm{NGF}$ receptor is also expressed outside the basal forebrain, notably in the mesencephalic trigeminal nucleus, cerebellar Purkinje cells, and striatal neurons (Pioro and Cuello, 1988, 1990a,b; Koh et al., 1989; Yan and Johnson, 1989; Altar, 1991; Bothwell, 1991b; Koh and Higgins, 1991; von Bartheld and Bothwell, 1993). There is evidence from in vivo and in vitro experiments that a population of noncholinergic, presumably GABAergic, basal forebrain neurons might also express the p75 NGF receptor (Batchelor et al., 1989; Dreyfus et al., 1990).

We found that $192 \mathrm{IgG}$-saporin injections affected two of these neuronal groups, cerebellar Purkinje cells after intraventricular injections and cholinergic striatal interneurons after basal forebrain injections. A subset of cerebellar Purkinje cells starts expressing the 75 NGF receptor during development and continues during adulthood (Pioro and Cuello, 1988, 1990b; Koh and Higgins, 1991). Striatal neurons express the p75 NGF receptor in early development but decrease the expression dras- tically during adulthood (Pioro and Cuello, 1990a; Altar, 1991; Koh and Higgins, 1991). The loss of striatal neurons might be due to the lesion-induced reexpression of p75 NGF receptors in the striatum (Gage et al., 1989). Striatal NADPHd-positive neurons were not affected by local injections. This is in line with previous observations that the $75 \mathrm{NGF}$ receptor in the striatum is expressed primarily by cholinergic neurons (Altar, 1991).

Most previous lesion studies of the basal forebrain did not find significant differences in noncholinergic neurotransmitter systems during the first months after basal forebrain lesions (for review, see Dekker et al., 1991; Reine and Nieoullon, 1992). The present study also did not find changes in the noradrenergic and dopaminergic fiber density in the cortex and hippocampus, which is in agreement with previous studies of the 192 IgGsaporin lesion model (Book et al., 1992; Nilsson et al., 1992).

In conclusion, $192 \mathrm{IgG}$-saporin appears to induce more complete lesions of neocortical and hippocampal cholinergic afferents than other previous lesion and toxin models. Lesions of other neuronal systems seem to be restricted to either cerebellar (after intraventricular injection) or striatal (after basal forebrain injection) neurons that present the p75 NGF receptor to the injected immunotoxin. The complete, selective, and relatively specific lesions induced by $192 \mathrm{IgG}$-saporin injections may be a useful tool to study the anatomical heterogeneity, physiology, and behavioral implications of the cholinergic basal forebrain system. 


\section{Appendix}

\section{Abbreviations}

a amygdala

ac anterior commissure

bl basolateral nucleus of amygdala

c cortex

ca cornu ammonis

Calb calbindin- $D_{28 k}$

ce central nucleus of amygdala

Ch 1 cholinergic cell group 1

Ch 2 cholinergic cell group 2

Ch 3 cholinergic cell group 3

Ch 4 cholinergic cell group 4

Ch 5 cholinergic cell group 5

Ch 6 cholinergic cell group 6

Ch 7 cholinergic cell group 7

cc corpus callosum

$\mathrm{cp} \quad$ caudate-putamen

DBH dopamine- $\beta$-hydroxylase

$\mathrm{dg} \quad$ dentate gyrus

gp globus pallidus

h hippocampus

$1 \quad$ lateral nucleus of amydala

L5 layer 5

Itn laterodorsal tegmental nucleus

$\mathrm{mh}$ medial habenula

ms medial septum

mpo magnoccllular prcoptic nuclcus

mtn mesencephalic trigeminal nucleus

nal nucleus ansae lenticularis

$\mathrm{nb}$ nucleus basalis

NGFr nerve growth factor receptor

nvl nucleus of the vertical limb of the diagonal band

ot olfactory tubercle

p putamen

Parv parvalbumin

ppn pedunculopontine nucleus

q cerebral aqueduct

rf rhinal fissure

rm raphe magnus nucleus

si substantia innominata

$t$ thalamus

TH tyrosine hydroxylase

vp ventral pallidum

\section{References}

Alonso JR, Covenas R, Lara J, Aijon J (1990) Distribution of parvalbumin immunoreactivity in the rat septal area. Brain Res Bull 24: $41-48$.

Altar CA (1991) Nerve growth factor and the neostriatum. Prog Neuropsychopharmacol Biol Psychiatry 15:157-169.

Altar CA, Bakhit C (1991) Receptor-mediated transport of human recombinant nerve growth factor from olfactory bulb to forebrain cholinergic nuclei. Brain Res 541:82-88.

Batchelor PE, Armstrong DM, Blaker SN, Gage FH (1989) Nerve growth factor receptor and choline acetyltransferase colocalization in neurons within the rat forebrain: response to fimbria-fornix transection. J Comp Neurol 284:187-204.

Bean AJ, Xu Z, Chai SY, Brimijoin S, Hökfelt T (1991) Effect of intracerebral injection of monoclonal acetylcholinesterase antibodies on cholinergic nerve terminals in the rat central nervous system. Neurosci Lett 133:145-149.

Bickel U, Kewitz. H (1990) Colocalization of choline acetyltransferase and nerve growth factor receptor in the rat basal forebrain. Dementia $1: 146-150$.

Boegman RJ, Cockhill J, Jhamandas K, Beninger RJ (1992) Excitotoxic lesions of rat basal forebrain: differential effects on choline acetyltransferase in the cortex and amygdala. Neuroscience 51:129-135.

Book AA, Wiley RG, Schweitzer JB (1992) Specificity of 192 IgGsaporin for NGF receptor-positive cholinergic basal forebrain neurons in the rat. Brain Res 590:350-355.

Bothwell M (1991a) Keeping track of neurotrophin receptors. Cell 65: 915-918.
Bothwell M (1991b) Tissue localization of nerve growth factor and nerve growth factor receptors. Curr Top Microbiol Immunol 165:5570.

Brauer K, Schober A, Wolff JR, Winkelmann E, Luppa H, Luth HJ, Bottcher H (1991) Morphology of neurons in the rat basal forebrain nuclei: comparison between NADPH-diaphorase histochemistry and immunohistochemistry of glutamic acid decarboxylase, choline acetyltransferase, somatostatin and parvalbumin. J Hirnforsch 32:1-17.

Carlsen J, Zaborszky L, Heimer L (1985) Cholinergic projections from the basal forebrain to the basolateral amygdaloid complex: a combined retrograde fluorescent and immunohistochemical study. J Comp Neurol 234:155-167.

Chang HT, Kuo H (1991) Relationship of calbindin D-28k and cholinergic neurons in the nucleus basalis of Meynert of the monkey and the rat. Brain Res 549:141-145.

Chao MV (1992) Neurotrophin receptors: a window into neuronal differentiation. Neuron 9:583-593.

Dawbarn D, Allen SJ, Semenenko FM (1988) Coexistence of choline acetyltransferase and nerve growth factor receptors in the rat basal forebrain. Neurosci Lett 94:138-144.

Dekker AJAM, Connor DJ, Thal LJ (1991) The role of cholinergic projections from the nucleus basalis in memory. Neurosci Biobehav Rev 15:299-317.

Dreyfus CF, Bernd P, Martinez HJ, Rubin SJ, Black IB (1990) Cellspecific expression of NGF receptors in the basal forebrain. In: Trophic factors and the nervous system (Horrocks $L \Lambda$, ed), pp 95-105. New York: Raven.

Dunnett SB, Everitt BJ, Robbins TW (1991) The basal forebraincortical cholinergic system: interpreting the functional consequences of excitotoxic lesions. Trends Neurosci 14:494-501.

Ferguson IA, Schweitzer JB, Bartlett PF, Johnson EM Jr (1991) Receptor-mediated retrograde transport in CNS neurons after intraventricular administration of NGF and growth factors. J Comp Neurol 313:680-692.

Fibiger HC (1991) Cholinergic mechanisms in learning, memory and dementia: a review of recent evidence. Trends Neurosci 14:220-223.

Fisher A, Hanin I (1986) Potential animal models for senile dementia of Alzheimer's type, with emphasis on AF64A-induced cholinotoxicity. Annu Rev Pharmacol Toxicol 26:161-181.

Freund TF (1989) GABAergic septohippocampal ncurons contain parvalbumin. Brain Res 478:375-381.

Gage FH, Bjorklund A, Stenevi U (1983) Reinnervation of the partially deafferented hippocampus by compensatory collateral sprouting from spared cholinergic and noradrenergic afferents. Brain Res 268 : 27-37.

Gage FH, Batchelor P, Chen KS, Chin D, Higgins GA, Koh S, Deputy S, Rosenberg MB, Fischer W, Bjorklund A (1989) NGF receptor reexpression and NGF-mediated cholinergic neuronal hypertrophy in the damaged adult neostriatum. Neuron 2:1177-1184.

Geula C, Schatz CR, Mesulam M-M (1993) Differential localization of NADPH-diaphorase and calbindin-D28K within the cholinergic neurons of the basal forebrain, striatum and brainstem in the rat, monkey, baboon and human. Neuroscience 54:461-476.

Henderson Z (1991) Sprouting of cholinergic axons docs not occur in the cerebral cortex after nucleus basalis lesions. Neuroscience 44:149156.

Henderson Z, Evans S (1991) Presence of a cholinergic projection from ventral striatum to amygdala that is not immunoreactive for NGF receptor. Neurosci Lett 127:73-76.

Hsu SM, Raine L, Fanger H (1981) Use of avidin-biotin-peroxidase complex $(\mathrm{ABC})$ in immunoperoxidase techniques: a comparison between $\mathrm{ABC}$ and unlabeled antibody (PAP) procedures. J Histochem Cytochem 29:577-580.

Imaizumi K, Kudo Y, Shiosaka S, Lee Y, Ikeda M, Ohta H, Matano $\mathrm{S}$, Stoji M, Honjoh T, Tohyama M (1991) Specific cholinergic destruction in the basal magnocellular nucleus and impaired passive avoidance behavior of rodents. Brain Res 551:36-43.

Kiss J, McGovern J, Patel AJ (1988) Immunohistochemical localization of cells containing nerve growth factor receptors in the different regions of the adult rat forebrain. Neuroscience 27:731-748.

Kiss J, Patel AJ, Baimbridge KG, Freund TF (1990a) Topographical localization of neurons containing parvalbumin and choline acetyltransferase in the medial septum-diagonal band region of the rat. Neuroscience 36:61-72.

Kiss J, Patel AJ, Freund TF (1990b) Distribution of septohippocampal 
neurons containing parvalbumin or choline acetyltransferase in the rat brain. J Comp Neurol 298:362-372.

Kitt CA, Levey AI, Friedman DP, Walker IC, Koliatsos VE, Raskin LS, Price DL (1988) Immunocytochemical visualization of cholinergic fibers in monkey neocortex: enhanced visualization using silver nitrate. Soc Neurosci $\Lambda$ bstr 14:631.

Koh S, Higgins GA (1991) Differential regulation of the low-affinity nerve growth factor receptor during postnatal development of the rat brain. J Comp Neurol 313:494-508.

Koh S, Oyler GA, Higgins GA (1989) Localization of nerve growth factor receptor messenger RNA and protein in the adult rat brain. Exp Neurol 106:209-221.

Kudo Y, Shiosaka S, Matsuda M, Tohyama M (1989) An attempt to cause the selective loss of the cholinergic neurons in the basal forebrain of the rat: a new animal model of Alzheimer's disease. Neurosci Lett 102:125-130.

I appi DA, Fsch FS, Barbieri I, Stirpe F, Soria M (1985) Characterization of a Saponaria officinalis seed ribosome-inactivating protein: immunoreactivity and sequence homologies. Biochem Biophys Res Commun 129:934-942.

Luiten PG, Spencer DG Jr, Traber J, Gaykema RP (1985) The pattern of cortical projections from the intermediate parts of the magnocellular nucleus basalis in the rat demonstrated by tracing with Phaseolus vulgaris-leucoagglutinin. Neurosci Lett 57:137-142.

Luiten PG, Gaykema RP, Traber J, Spencer DG Jr (1987) Cortical projection patterns of magnocellular basal nucleus subdivisions as revealed by anterogradely transported Phaseolus vulgaris leucoagglutinin. Brain Res 413:229-250.

Lysakowski A, Wainer BH, Bruce G, Hersh LB (1989) An atlas of the regional and laminar distribution of choline acetyltransferase immunoreactivity in rat cerebral cortex. Neuroscience 28:291-336.

Masson P (1928) Carcinoids (argentaffin-cell tumors) and nerve hyperplasia of the appendicular mucosa. Am J Pathol 4:181-211.

McGurk SR, Hartgraves SL, Kelly PH, Gordon MN, Butcher LL (1987) Is ethylcholine mustard aziridinium ion a specific cholinergic neurotoxin? Neuroscience 22:215-224.

Mesulam M-M (1988) Central cholinergic pathways: neuroanatomy and some behavioral implications. In: Neurotransmitters and cortical function: from molecules to mind (Avoli M, Reader TA, Dykes RW, Gloor P, eds), pp 237-260. New York: Plenum.

Mesulam M-M, Asuncion Moran M (1987) Cholinesterases within neurofibrillary tangles related to age and Alzheimer's disease. Ann Neurol 22:223-228.

Mesulam MM, Mufson EJ, Wainer BH, Levey AI (1983) Central cholinergic pathways in the rat: an overview based on an alternative nomenclature (Ch1-Ch6). Neuroscience 10:1185-1201.

Mufson EJ, Kehr AD, Wainer BH, Mesulam M-M (1987) Cortical effects of neurotoxic damage to the nucleus basalis in rats: persistent loss of extrinsic cholinergic input and lack of transsynaptic effect upon the number of somatostatin-containing, cholinesterase-positive, and cholinergic cortical neurons. Brain Res 417:385-388.

Nagai T, Kimura H, Maeda T, McGeer PL, Peng F, McGeer EG (1982) Cholinergic projections from the basal forebrain of rat to the amygdala. J Neurosci 2:513-520.

Nakamura S, Tani Y, Maezono Y, Ishihara T, Ohno T (1992) Learning deficits after unilateral AF64A lesions in the rat basal forebrain: role of cholinergic and noncholinergic systems. Pharmacol Biochem Behav 42:119-130.

Nilsson OG, Leanza G, Rosenblad C, Lappi DA, Wiley RG, Bjorklund A (1992) Spatial learning impairments in rats with selective immunolesion of the forebrain cholinergic system. Neuroreport 3:10051008 .

Olton DS, Wenk GL (1987) Dementia: animal models of the cognitive impairments produced by degeneration of the basal forebrain cholinergic system. In: Psychopharmacology: the third generation of progress (Meltzer HY, ed), pp 941-953. New York: Raven.

Pasqualotto BA, Vincent SR (1991) Galanin and NADPH-diaphorase coexistence in cholinergic neurons of the rat basal forebrain. Brain Res 551:78-86.
Paxinos G, Watson C (1986) The rat brain in stereotaxic coordinates. San Diego: Academic.

Pioro EP, Cuello AC (1988) Purkinje cells of adult rat cerebellum express nerve growth factor receptor immunoreactivity: light microscopic observations. Brain Res 455:182-186.

Pioro EP, Cucllo AC (1990a) Distribution of nerve growth factor receptor-like immunoreactivity in the adult rat central nervous system. Effect of colchicine and correlation with the cholinergic system I. Forebrain. Neuroscience 34:57-87.

Pioro EP, Cuello AC (1990b) Distribution of nerve growth factor receptor-like immunoreactivity in the adult rat central nervous system. Effect of colchicine and correlation with the cholinergic systemII. Brainstem, cerebellum and spinal cord. Neuroscience 34:89-110.

Rakonczay Z, Hammond P, Brimijoin S (1993) Lesion of central cholinergic systems by systemically administered acetylcholinesterase antibodies in newborn rats. Neuroscience $54: 225-238$.

Rao ZR, Shiosaka S, Tohyama M (1987) Origin of cholinergic fibers in the basolateral nucleus of the amygdaloid complex by using sensitive double-labeling technique of retrograde biotinized tracer and immunocytochemistry. J Hirnforsch 28:553-560.

Reine G, Nieoullon A (1992) Neurobiochimie des lésions expérimentales du noyau basal de Meynert. Rev Neurol (Paris) 148:24-38.

Robbins TW, Everitı BJ, Ryan CN, Marston HM, Jones GH, Page KJ (1989) Comparative effects of quisqualic and ibotenic acid-induced lesions of the substantia innominata and globus pallidus on the acquisition of a conditional visual discrimination: differential effects on cholinergic mechanisms. Neuroscience 28:337-352.

Rye DB, Wainer BH, Mesulam MM, Mufson EJ, Saper CB (1984) Cortical projections arising from the basal forebrain: a study of cholinergic and noncholinergic components employing combined retrograde tracing and immunohistochemical localization of choline acetyltransferase. Neuroscience 13:627-643.

Scherer-Singler U, Vincent SR, Kimura H, McGeer EG (1983) Demonstration of a unique population of neurons with NADPH-diaphorase histochemistry. J Neurosci Methods 9:229-234.

Schweitzer JB (1987) Nerve growth factor receptor-mediated transport from cerebrospinal fluid to basal forebrain neurons. Brain Res 423: 309-317.

Smith G (1988) Animal models of Alzheimer's disease: experimental cholinergic denervation. Brain Res 472:103-118.

Sternberger LA (1986) Immunocytochemistry. New York: Wiley.

Tago H, Kimura H, Maeda T (1986) Visualization of detailed acetylcholinesterase fiber and neuron staining in rat brain by a sensitive histochemical procedure. J Histochem Cytochem 34:1431-1438.

von Bartheld CS, Bothwell M (1993) Development of the mesencephalic nucleus of the trigeminal nerve in chick embryos: target innervation, neurotrophin receptors, and cell death. J Comp Neurol 328:185-202.

Wainer BH, Mesulam M-M (1990) Ascending cholinergic pathways in the rat brain. In: Brain cholinergic systems (Steriade M, Biesold D, eds), pp 65-119. New York: Oxford UP.

Wiley RG (1992) Neural lesioning with ribosome-inactivating proteins: suicide transport and immunolesioning. Trends Neurosci 15: 285-290.

Wiley RG, Lappi DA (1993) Preparation of anti-neuronal immunotoxins for selective neural immunolesioning. Elsevier Neurosci Protocols, in press.

Wiley RG, Oeltmann TN, Lappi DA (1991) Immunolesioning: selective destruction of neurons using immunotoxin to rat NGF receptor. Brain Res 562:149-153.

Woolf NJ, Butcher LL (1982) Cholinergic projections to the basolateral amygdala: a combined Evans blue and acetylcholinesterase analysis. Brain Res Bull 8:751-763.

Woolf NJ, Gould E, Butcher LL (1989) Nerve growth factor receptor is associated with cholinergic neurons of the basal forebrain but not the pontomesencephalon. Neuroscience 30:143-152.

Yan Q, Johnson EM Jr (1989) Immunohistochemical localization and biochemical characterization of nerve growth factor receptor in adult rat brain. J Comp Neurol 290:585-598. 